\title{
Políticas de Precificação do Setor de Saneamento Urbano no Brasil: As Evidências do Equilíbrio de Baixo Nível
}

\author{
Ricardo Coelho de Faria \\ Jorge Madeira Nogueira \\ Bernardo Mueller
}

Professor da Universidade Católica de Brasília

Professor Titular do Departamento de Economia da Universidade de Brasília Professor Adjunto do Departamento de Economia da Universidade de Brasília

\section{RESUMO}

O artigo analisa a existência do Equilíbrio de Baixo Nível no setor de saneamento urbano brasileiro, de acordo com o modelo de Spiller e Savedoff (1999). Neste tipo de equilíbrio existe um círculo vicioso entre o oportunismo do governo, preços abaixo dos custos de fornecimento, ausência de investimentos e a baixa qualidade dos serviços de utilidade pública. A exemplo de outros países da América Latina, os resultados demonstram que, com poucas exceções, a qualidade dos serviços de abastecimento urbano de água e de esgotamento sanitário no Brasil é de baixo nível. Este resultado está associado ao modelo institucional e regulatório adotado. No entanto, as particularidades no caso brasileiro deixam mais evidente que o baixo nível está também associado às condições econômicas, uma vez que os estados e municípios de maior renda possuem serviços de alta qualidade, independentemente do sistema regulatório.

\section{PALAVRAS-CHAVE}

saneamento, política de preços, regulação, equilíbrio debaixo nível

ABSTRACT

The existence of a low level equilibrium balance in the supply of urban sewage services is analysed in this essay. The low level equilibrium hypothesis is related to the model by Spiller e Savedoff (1999) for Latin American countries. In their view, government opportunism and populism lead towards prices below costs of providing sewage service in developing countries. This is the starting point of a vicious circle, leading towards low quality of public utility services. Like other countries in Latin America, data for Brazil demonstrate that, with few exceptions, the low level equilibrium of water and sewage supply services in urban areas. However, some particularities in the Brazilian reality suggest that this low level equilibri-

um may be explained in economic terms. It is shown that wealthier states and municipalities provide high quality services, regardless of the regulatory system.

KEY WORDS low level equilibrium, public provided water and sewage services, regulation, price policy

JEL Classification L5I, O57, Q25 


\section{INTRODUÇÃO}

As reformas nos setores de abastecimento de água e de esgotamento sanitário têm integrado a agenda política de países em desenvolvimento. Em geral, esses setores são caracterizados por baixos índices de cobertura e de qualidade dos serviços. Diversos estudos têm procurado explicar as dificuldades encontradas pelas reformas e identificar os elementos essenciais para que elas sejam bem-sucedidas. Para Ménard e Shirley (2001), dois fatores são fundamentais para entender as mudanças institucionais no setor: um político e outro econômico. As reformas no setor de abastecimento de água constituem um processo altamente politizado, principalmente porque a água ainda é vista como um bem livre e que afeta toda a população. $\mathrm{O}$ fator econômico relevante diz respeito aos riscos do setor, especialmente pelo volume de investimentos necessários para a operação dos serviços de abastecimento e de esgotamento sanitário.

Enfatizando os aspectos políticos que envolvem o setor, Spiller e Savedoff (1999) definiram Equilíbrio de Baixo Nível como resultante das políticas desenvolvidas em alguns países da América Latina. Nesses países, o arranjo institucional cria um oportunismo para o governo interferir de forma prejudicial nos ajustes tarifários do setor. Há uma tendência à fixação de tarifas abaixo do nível financeiramente recomendável, causando redução no nível de investimentos e queda na qualidade do serviço. No Brasil, em particular, vários estudos têm surgido e apresentado argumentos semelhantes (SILVA, 1995a; EMERCIANO \& BALTAR, 1995; PEREIRA, BALTAR \& ABICALIL, 1995; e REZENDE et alii, 1995), indicando a necessidade de reformas no setor, devido às dificuldades enfrentadas.

O presente artigo analisa o Equilíbrio de Baixo Nível para os setores de abastecimento urbano de água e de esgotamento sanitário no Brasil. $\mathrm{O}$ artigo está dividido em mais três seções além desta introdução. Na seção 1 é feita uma breve apresentação da base teórica desenvolvida por Spiller e Savedoff (1999) para explicar a performance dos sistemas de abastecimento urbano de água em alguns países da América Latina, cujo resultado é definido como sendo o Equilíbrio de Baixo Nível. Na seção 2, tal modelo é analisado para o caso brasileiro, destacando-se as principais características do sistema regulatório e as evidências do Equilíbrio de Baixo Nível. A última seção sintetiza os resultados do estudo.

\section{O MODELO DE EQUILÍBRIO DE BAIXO NÍVEL}

Analisando a regulação do setor de abastecimento de água em alguns países da América Latina, Spiller e Savedoff (1999) observaram que os respectivos governos tendem a fixar os preços abaixo do nível financeiro sustentável, descapitalizando as empresas pú- 
blicas e privadas que fornecem os serviços. O resultado dessa política é a queda na qualidade de tais serviços e um baixo índice de cobertura. Com esse resultado, os consumidores tornam-se resistentes a aumentos de preços, pois não acreditam na melhoria dos serviços. Há, portanto, falta de suporte político para que o governo possa reverter a situação mediante aumento de preços.

De acordo com Spiller e Savedoff $(1999$, p. 2) a política de preços baixos descapitaliza as empresas de fornecimento d'água, cuja tarifa é suficiente apenas para pagar os salários, não sustentando os investimentos necessários para expansão e melhoria dos serviços. No caso em que o serviço de abastecimento é fornecido por uma empresa pública, a expansão e a qualidade dos serviços ficam totalmente dependentes das transferências orçamentárias do governo central. Como o orçamento é limitado e disputado com outros serviços públicos, o resultado é a ineficiência operacional das empresas públicas de abastecimento, que fornecem serviços de baixa qualidade e deixam de expandir o fornecimento para novos bairros. Tal arranjo institucional e a falta de suporte político estimulam o "oportunismo" para que o governo mantenha a política de preços baixos, gerando um círculo vicioso, que é caracterizado por um "Equilíbrio de Baixo Nível". A Figura 1 mostra uma estrutura esquemática desse modelo de regulação.

Por outro lado, esse modelo, adicionado à falta de credibilidade, transforma-se em ponto crítico para a efetiva participação do setor privado na provisão de água. Uma operadora privada buscará maximizar seu lucro e minimizar o risco. Então, caso ela já esteja operando no setor, a política de preços baixos leva a empresa a minimizar suas perdas mediante a redução dos custos e dos investimentos para um nível aquém daquele que seria necessário para garantir a qualidade e a cobertura dos serviços. Além do mais, essa política dificilmente atrairá investimentos de novas empresas. Assim, de uma forma ou de outra, o modelo de regulação produz uma estabilidade no sistema com um Equilíbrio de Baixo Nível, cuja ruptura é de difícil solução.

Não obstante, o Equilíbrio de Baixo Nível tem altos custos sociais. Assim, sair deste equilíbrio deve ser uma prioridade para o governo. Na realidade, os governos só adotam políticas de preços baixos devido à falta de suporte político. Segundo Spiller e Savedoff (1999), algumas estratégias adotadas para a solução do problema são claramente falhas. Em primeiro lugar, aumentar o preço sem definir as regras institucionais de como devem ser corrigidos não é uma medida sustentável. 


\section{FIGURA 1 - REPRESENTAÇÃO ESQUEMÁTICA DO EQUILÍBRIO DE BAIXO NÍVEL}

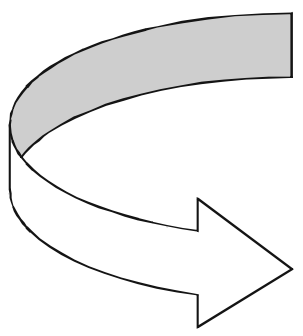

Preços baixos

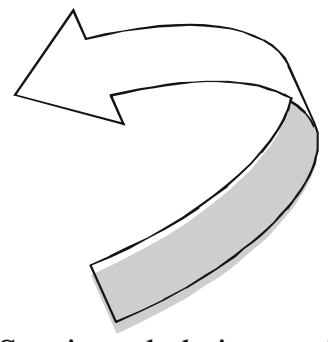

Serviços de baixa qualidade e corrupção

\footnotetext{
- Paga apenas salários

- Investimentos limitados

- Dependência das transferências do governo
}

- Baixa cobertura

- Racionamento

- Desvio de verbas

- Superemprego

Fonte: SPILLER \& SAVEDOFF (1999, p. 14).

Outro tipo de estratégia sem sucesso tem sido a introdução de um novo sistema de gestão de empresas públicas com base nos contratos de performance. Esses contratos são efetuados entre a gestão e o governo, em que a primeira recebe alguma parte do lucro incrementado. Mas, como demonstrado em Shirley e Xu (apud SPILLER \& SAVEDOFF, 1999), tais contratos não têm obtido êxito porque os mesmos não mudam o poder discricionário do governo e ainda criam assimetria de informação entre gestão e governo. Como os gestores sabem que o governo (ou os consumidores) pode se apropriar do excedente a qualquer momento, preferem distribuir os recursos entre eles mesmos e não investir na eficiência dos serviços.

Uma terceira estratégia é implementar um sistema de contratos do tipo BOTs - Build, Operate and Transfer, que são contratos de prestação de serviços firmados entre governo e firmas privadas. ${ }^{1}$ Este tipo de reforma é atrativo, porque permite adicionar capacidade sem causar distúrbio no interesse público e não requer mudança fundamental no caminho que a companhia opera, além de não exigir transferências diretas do governo. No entanto, o sistema requer uma substancial garantia do governo em termos de preço e de cumprimento de cláusulas contratuais. Porém, se o problema de credibilidade não

1 Os BOTs são uma modalidade de participação do setor privado pelo qual o poder concedente mantém o controle do sistema, mas os ativos são transferidos à propriedade privada. Outra característica desse tipo de contrato é que a cobrança das tarifas aos usuários não é realizada pelo contratado. (PEREIRA, BALTAR \& ABICALIL, 1995, p. 38). 
for resolvido, a implementação dos BOTs é entendida pela opinião pública como sendo mais um favoritismo, resultando, do mesmo modo, em uma solução de alto custo político. Fica claro, então, que tais medidas não são suficientes para provocar uma ruptura na estabilidade do Equilíbrio de Baixo Nível.

Spiller e Savedoff (1999, p. 20) argumentam que o ponto chave é desenvolver um processo que limite o poder discricionário do governo na formação do preço. Todavia, para que esse processo seja efetivo é necessário que o operador tenha uma substancial autonomia financeira e gerencial, além de três mecanismos apresentados por Levy e Spiller (apud SPILLER \& SAVEDOFF 1999, p. 20), quais sejam: i) as restrições mais importantes do sistema regulatório devem estar incluídas de uma forma clara na estrutura regulatória; ii) as restriçôes devem limitar a possibilidade de o político mudar as regras do jogo (base legal da estrutura regulatória); e iii) é preciso que haja instituições responsáveis para monitorar o cumprimento das regras. Essas medidas implicam, naturalmente, a modelagem de um sistema descentralizado.

Vários países da América Latina possuem um sistema de provisão de água com características semelhantes às descritas por Spiller e Savedoff (1999). Embora cada país apresente suas particularidades, a maior parte dos elementos discutidos acima está presente em suas estruturas regulatórias. Em Honduras, Walker et alii (1999) verificaram que o setor continua dependendo de fundos externos para realizar investimentos e que as empresas de provisão de água ainda operam de forma ineficiente. Os consumidores estão relativamente pouco dispostos a aceitar um aumento das tarifas para melhorar os serviços por meio de empresas públicas.

No Peru, segundo Tamayo et alii (1999), desde 1990 tenta-se implementar reformas no sentido de descentralizar as decisões relacionadas ao setor de abastecimento urbano de água. No entanto, algumas companhias municipais ainda operam de forma ineficiente e o sistema continua no ciclo do Equilíbrio de Baixo Nível. A situação não é muito diferente no México. Desde os anos 1980 o país vem tomando medidas com o intuito de melhorar os índices de cobertura. Ozuna e Gómez (1999) fizeram uma avaliação econométrica em mais de 200 companhias de abastecimento e detectaram que elas operam com pouca economia de escala. Identificaram também que a nova lei de gestão de recursos hídricos não tem produzido impacto significativo no sistema.

De acordo com Morandé e Doña (1999) os serviços de abastecimento e saneamento no Chile têm mudado de um setor público centralizado para um sistema mais descentralizado, inclusive com o envolvimento do setor privado. A estratégia de subsidiar o fornecimento de água para classes mais pobres tem sido uma política aceitável, permitindo, com isso, uma razoável recuperação das tarifas em decorrência de uma menor resistência por parte do público. Já na Argentina, o setor de abastecimento urbano de 
água tem sido, tradicionalmente, gerido pelo setor público. Entretanto, nos últimos 10 anos o país tem experimentado a participação privada no setor. Segundo Artana et alii (1999), na Argentina as duas primeiras grandes concessões ocorreram na província de Corrientes e na cidade de Buenos Aires. Porém, diferenças na estrutura regulatória e no contexto institucional dessas concessões podem ter afetado os resultados das companhias que operam nessas áreas.

Recentemente, Ménard e Shirley (2001) analisaram as reformas políticas no setor de saneamento em seis grandes cidades de países em desenvolvimento: Abidjan, Buenos Aires, Conakry, Lima, Cidade do México e Santiago do Chile. Nesse estudo os autores demonstraram como o oportunismo pode conduzir a motivação para as reformas, bem como definir seus desenhos e seus resultados. Com relação à política tarifária, eles indicam que em Lima e na Cidade do México as tarifas são determinadas e ajustadas de modo ad hoc, de acordo com critérios políticos, contribuindo para o insucesso das reformas.

Em suma, pode-se depreender dos estudos analisados que, de uma forma ou de outra, o setor de abastecimento urbano de água tem apresentado uma estabilidade em torno do Equilíbrio de Baixo Nível. Em todos eles, o sistema regulatório é fortemente caracterizado pelo oportunismo do governo central, adotando políticas de preços inadequadas para o nível financeiro sustentável das companhias responsáveis pela provisão desse tipo de serviço de utilidade pública. Em geral, as mudanças nos arranjos institucionais não têm sido suficientes para provocar a ruptura do Equilíbrio de Baixo Nível.

\section{EXISTE O EQUILÍBRIO DE BAIXO NÍVEL NO BRASIL?}

Será que uma estabilidade em torno do Equilíbrio de Baixo Nível também é característica do setor de saneamento brasileiro, particularmente nos seguimentos de abastecimento de água e esgotamento sanitário? Para responder a essa questão analisamos os indicadores constantes da Figura 1, conforme originalmente apresentados por Spiller e Savedoff (1999). Mais especificamente, foi desenvolvida uma análise considerando-se a seqüência de "causa-efeito" da representação esquemática do modelo: i) os indicadores de qualidade (serviços de baixa qualidade) ${ }^{2}$ ii) a política de preços e os investimentos no setor (preços baixos); e iii) o arranjo institucional e as condições de oportunismo do governo para interferir nos preços (governo). Para facilitar a compreensão do leitor, essa seção está estruturada refletindo a ordem seqüiencial do modelo.

2 Os aspectos de corrupção abordados por SPILLER \& SAVEDOFF (1999) não são tratados neste trabalho, essencialmente devido à dificuldade de evidenciar esse tipo de resultado possível. 


\subsection{A Qualidade dos Serviços}

No Brasil, historicamente, os serviços de saneamento foram, e ainda continuam sendo, exercidos quase que integralmente por prestadores de direito público (empresas públicas, autarquias, empresas de economia mista, departamentos municipais etc.). A Tabela 1 apresenta uma visão geral de uma amostra de 198 prestadores de serviços distribuídos em todo o País. ${ }^{3}$ Por outro lado, e de acordo com o Sistema Nacional de Informações sobre Saneamento - SNIS, os prestadores de serviços são classificados com base em sua área de abrangência (prestadores de serviços de abrangência regional, microrregional e local) ${ }^{4}$ e sua natureza administrativa (de direito público ou de direito privado). 5

TABELA 1 - DISTRIBUIÇÃO DOS PRESTADORES DE SERVIÇOS, SEGUNDO SUA ÁREA DE ABRANGÊNCIA E CARACTERÍSTICAS DO ATENDIMENTO

\begin{tabular}{|c|c|c|c|c|c|}
\hline \multicolumn{2}{|c|}{ Prestadores de serviços } & \multicolumn{2}{|c|}{$\begin{array}{l}\text { População urbana dos } \\
\text { Municípios atendidos }\end{array}$} & \multicolumn{2}{|c|}{ Quantidade de municípios atendidos } \\
\hline Abrangência & Quant. & $\begin{array}{l}\text { Água } \\
\text { (milhões) }\end{array}$ & $\begin{array}{l}\text { Esgotos } \\
\text { (milhões) }\end{array}$ & Água & Esgotos \\
\hline$\overline{R e g i o n a l ~(*)}$ & 27 & 100,6 & 69,5 & 3.890 & 748 \\
\hline Microrregional & 5 & 0,8 & 0,1 & 14 & 4 \\
\hline Local & 166 & 18,9 & 17,4 & 165 & 100 \\
\hline Total & 198 & 120,3 & 98,0 & 4.069 & 852 \\
\hline
\end{tabular}

Fonte: Diagnóstico dos Serviços de Água e Esgotos - 1999/ Sistema Nacional de Informações sobre Saneamento - SNIS/ SEDU/IPEA.

${ }^{*}$ ) Inclui 26 companhias estaduais e uma autarquia estadual.

3 Estes prestadores de serviços participaram da amostra do Diagnóstico dos Serviços de Água e Esgotos de 1999 do SNIS - Sistema Nacional de Informações sobre Saneamento. O SNIS é coordenado por uma parceria entre a Secretaria Especial de Desenvolvimento Urbano (SEDU) e o Instituto de Pesquisa Econômica Aplicada (IPEA) e constitui-se na principal fonte de dados deste trabalho.

4 São considerados serviços regionais aqueles que abrangem diversos municípios, onde se incluem as atuais companhias estaduais. Os serviços microrregionais são aqueles que operam um único conjunto de sistemas de um pequeno número de municípios. Já os serviços locais são constituídos por aqueles que atendem a um único município, mesmo que mediante a operação de mais de um sistema.

5 No que diz respeito à natureza administrativa, os prestadores de serviços podem ser classificados em de direito público e privado. No primeiro grupo estão as entidades cujos serviços municipais são administrados diretamente (por intermédio de departamentos da prefeitura) ou por autarquias. São de direito privado as empresas públicas, as sociedades de economia mista, as empresas privadas e as organizaçóes sociais. (Diagnóstico dos Serviços de Água e Esgotos, 1999, p. 5, SNIS). 
Considerando a quantidade total de 5.507 municípios no País e uma população urbana de 129,7 milhões de habitantes, ${ }^{6}$ os dados da Tabela 1 deixam evidente a representatividade da amostra considerada pelo Diagnóstico de 1999 do SNIS. Fica também evidente a importância dos serviços prestados pelas 27 companhias estaduais que têm abrangência regional, tanto em termos da população atendida quanto do número de municípios. Uma constatação imediata, com base nos dados da Tabela 1 , é a significativa discrepância entre os atendimentos em termos de água e esgoto, sendo este último tipo de serviço muito inferior ao primeiro. Não obstante, tanto os serviços de água como de esgotamento sanitário têm sido disponibilizados para uma parcela crescente de domicílios. Entre 1992 e 1999, houve um incremento de 7,5\% e 9,4\% no número de domicílios atendidos com água e esgotamento, respectivamente. ${ }^{7}$

No caso particular do abastecimento de água, o País está próximo de conseguir a universalização dos serviços, especialmente nas regiões Sul e Sudeste. Em contraste, o Estado do Piauí e, de modo geral, a Região Norte, apresentam níveis de atendimento muito baixos. Alguns estados, inclusive, pioraram a situação no período 1992/1999, com seus índices se assemelhando àqueles existentes em países como Honduras (WALKER, 1999, p. 38), Peru (TAMAYO, 1999, p. 97), México (OZUNA \& GÓMEZ, 1999, p. 140) e Argentina (SPILLER \& SAVEDOFF, 1999, p. 16). Quanto aos índices de atendimento de esgoto com rede coletora, a situação é mais dramática. Com poucas exceções, pode-se dizer que tais serviços apresentam uma condição de "baixo nível". Na realidade, tomando-se como base o ano de 1999, apenas os Estados de Minas Gerais, São Paulo (e suas respectivas regiões metropolitanas) e o Distrito Federal possuem índices de cobertura de água superiores a 90\% e índices de coleta de esgoto superiores a $80 \%$, podendo, portanto, serem excluídos da categoria de baixo nível. $^{8}$

Outra característica do Equilíbrio de Baixo Nível é o superemprego no setor. A Tabela 2 apresenta uma distribuição de freqüêencia do número de empregados por mil ligações de água, segundo alguns intervalos de classes. De modo geral, nossos indicadores não se diferenciam muito daqueles existentes em países como Honduras, México, Peru e Argentina. Dos 186 serviços analisados, mais de 76\% possuem 4 ou mais empregados por 1.000 ligaçôes de água, sinalizando a possibilidade de "empreguismo" e a inefici-

6 Idem, com base nas estimativas da população projetada pelo IBGE para 1999 e nos índices de urbanização da Contagem de 1996.

7 A Tabela A do anexo mostra os índices de atendimento de água e de esgoto por Regiões, Unidades da Federação e Regiões Metropolitanas, referentes aos anos de 1992 e 1999.

8 Não existe uma definição clara do que seja baixo ou alto nível, o que dificulta qualquer delimitação no sentido acima. A rigor, um serviço poderia ser considerado como de alto nível se atingisse o índice de $100 \%$ de cobertura, uma vez que a universalização é a meta ideal para qualquer sociedade. No entanto, a manutenção desse índice ideal é difícil até mesmo para alguns países desenvolvidos. Nesse sentido, é razoável considerar aqueles serviços com índices próximos da universalização como sendo de alto nível. 
ência operacional do setor. ${ }^{9}$ Esse indicador não revela, no entanto, diferenças bruscas entre os tipos de prestadores de serviços. ${ }^{10}$ As estatísticas mostram apenas que tais indicadores têm sido mais homogêneos entre as empresas privadas, mas sem haver um ganho significativo em termos de eficiência. ${ }^{11}$ É possível que esse ganho ainda não tenha ocorrido por causa do prazo curto das concessões, pois algumas delas iniciaram sua operação ainda em 1999, quando essas informações foram levantadas.

\begin{tabular}{|c|c|c|c|c|}
\hline \multirow{3}{*}{$\begin{array}{l}\text { Empregados/ } \\
1.000 \text { ligações } \\
\text { Classes }\end{array}$} & \multirow{3}{*}{$\begin{array}{c}\text { Freqüência } \\
\text { Total }\end{array}$} & \multicolumn{3}{|c|}{ Freqüência por grupo } \\
\hline & & \multirow{2}{*}{$\begin{array}{l}\text { Regionais } \\
\text { CESBs }^{1}\end{array}$} & \multicolumn{2}{|c|}{ Microrregionais e locais } \\
\hline & & & Públicos & Privados $^{2}$ \\
\hline 0 |------- 2 & 3 & - & 3 & - \\
\hline 2 |------- 4 & 41 & 11 & 27 & 3 \\
\hline 4 |------- 6 & 72 & 9 & 58 & 5 \\
\hline 6 |------- 8 & 39 & 2 & 32 & 5 \\
\hline 8 |------- 10 & 18 & 2 & 15 & 1 \\
\hline 10 oumais & 13 & 2 & 10 & 1 \\
\hline Total & 186 & 26 & 145 & 15 \\
\hline
\end{tabular}

Fonte: Diagnóstico dos Serviços de Água e Esgoto - 1999/SNIS.

(1) Este indicador não foi obtido para o caso da CAESA/AP. (2) Serviços que estão sob concessão privada. Fonte: ABCON - Associação Brasileira das Concessionárias de Serviços de Água e Esgoto. Situação atualizada em setembro/200l. Estão incluídos aqueles serviços que tiveram data inicial de operação em 1999 ou antes e participaram do SNIS 1999.

No que diz respeito ao racionamento, a questão não parece tão dramática quanto a de outros indicadores. Os dados da Tabela 3 mostram que a quantidade de horas de operação por dia nos sistemas de distribuição de água está próxima daquela conseguida no Chile, sendo, portanto, bastante superior aos índices de Honduras, México e Peru (veja SPILLER \& SAVEDOFF, 1999, p. 16). Neste caso é possível identificar uma sutil di-

9 Como no caso da deficiência do conceito do que seja baixo ou alto nível, o conceito de "empreguismo" também não possui uma delimitação precisa. Neste sentido, a saída é comparar o indicador com os sistemas de provisão d'água que são assumidos como sendo mais eficientes pela literatura especializada. Para a América Latina, o sistema de abastecimento de água do Chile é citado como uma referência de bom desempenho em vários aspectos, inclusive com relação ao número de empregados utilizados: 2,5 empregados por 1.000 conexões. (SPILLER \& SAVEDOFF, 1999, p. 16).

10 Dentre as Companhias estaduais (CESBs), 11 delas possuíam menos de 4 empregados por mil ligações em 1999: CAGECE, CAGEPA, COMPESA, DESO e EMBASA, no Nordeste; CESAN e SABESP, no Sudeste; CASAN, CORSAN e SANEPAR, no Sul. De outro lado, a DEAS (no Norte) e a SANEMAT (no Centro-Oeste) tinham os piores indicadores.

11 A Tabela B do Anexo mostra os indicadores para cada uma das Companhias estaduais (CESBs) e para cada um dos municípios que concederam os serviços de saneamento a empresas privadas. 
ferença entre os grupos de prestadores de serviços, uma vez que os municípios atendidos por empresas privadas praticamente não sofreram problemas de interrupções sistemáticas, o que indica ausência da necessidade de racionamento. Já aqueles municípios atendidos pelas companhias estaduais (CESBs) tiveram um atendimento de, em média, 22,4 horas por dia ao longo do ano de 1999, com interrupçóes ocorrendo de maneira mais heterogênea.

Com relação à qualidade da água distribuída, a Portaria no 36/GM do Ministério da Saúde estabelece normas e padrões de potabilidade que devem ser observadas em todo o território nacional. Um dos indicadores existentes refere-se à quantidade de amostras de coliformes fecais fora do padrão: 9\% dos 314 municípios que forneceram essa informação apresentaram resultados muito abaixo do padrão determinado por Lei. (Diagnóstico dos Serviços de Água e Esgotos, 1999, p. 41). ${ }^{12}$

\section{TABELA 3 - HORAS DE OPERAÇÃO POR DIA NOS SISTEMAS DE DIS- TRIBUIÇÃO DE ÁGUA ${ }^{1}$}

\begin{tabular}{lccccc}
\hline Prestadores & Quant. & \multicolumn{4}{c}{ Estatísticas } \\
\cline { 3 - 6 } de serviços & & Média & Máx. & Min. & Desvio padrão \\
& & Horas/dia & Horas/dia & Horas/dia & Horas/dia \\
\hline CESBs $^{2}$ & 117 & 22,4 & 24,0 & 8,6 & 3,5 \\
Municipais Públicos & 95 & 23,3 & 24,0 & 5,6 & 2,7 \\
Municipais Privados & 9 & 24,0 & 24,0 & 23,9 & 0,0 \\
Total & 221 & 22,9 & 24,0 & 5,6 & 3,1 \\
\hline
\end{tabular}

Fonte: Estimativas com base nos dados do Diagnóstico dos Serviços de Água e Esgotos - 1999/SNIS.

(1) A quantidade de horas foi estimada subtraindo-se a duração média diária das intermitências prolongadas em cada município.

(2) Alguns dados dos municípios atendidos pelas CESBs foram desconsiderados por apresentarem inconsistência, especialmente aqueles informados pela Companhia do Estado do Rio Grande do Sul.

(3) Serviços que estão sob concessão do setor privado. Fonte: ABCON - Associação Brasileira das Concessões de Serviços de Água e Esgoto. Situação atualizada em setembro/2001. Estão incluídos aqueles serviços que tiveram data inicial de operação em 1999 ou antes e participaram do SNIS 1999.

Em suma, de um modo geral os serviços de abastecimento urbano de água e de esgotamento sanitário podem ser qualificados com sendo de baixo nível em termos de índices de cobertura e do superemprego no setor. Em termos de cobertura, apenas alguns casos isolados não merecem tal qualificação, principalmente os serviços localizados nas regiôes mais ricas do País. Destacam-se os níveis de atendimento do Estado de São

12 O SNISS divulga também outros indicadores de qualidade, tais como o teor de cloro residual na água e o teor de turbidez da água. No entanto, como a literatura sobre o equilíbrio de baixo nível não tem utilizado esses indicadores, optamos também por não utilizá-los, já que tornaria as comparações com outros países mais dificultosa. 
Paulo e Minas Gerais, no Sudeste, e do Distrito Federal, no Centro-Oeste. Os Estados do Sul apresentam bons indicadores em termos de atendimento de água, mas deixam a desejar em termos do porcentual de domicílios com rede coletora de esgoto, com exceção da Região Metropolitana de Curitiba, que apresenta bons indicadores tanto em termos de água quanto de esgoto.

\subsection{A Politica de Preços Baixos e os Investimentos no Setor}

Até 1978, a prática tarifária no Brasil era conduzida de forma isolada, sem qualquer sistematização de procedimentos, tanto no que diz respeito à base de custos adotada quanto à política de reajustes periódicos. ${ }^{13}$ Para disciplinar a situação, segundo Holanda (1995, p. 57), a Lei n. ${ }^{\circ} 6.528 / 78$ atribuiu ao Ministério do Interior a responsabilidade de estabelecer normas gerais de tarifação, coordenar, orientar e fiscalizar a execução de serviços de saneamento e assegurar a assistência financeira quando necessária. Estabelecia, também, que a determinação das tarifas deveria considerar o equilíbrio econômico-financeiro das companhias estaduais, ${ }^{14}$ bem como os aspectos sociais dos serviços de saneamento. Neste sentido, as tarifas seriam diferenciadas segundo as categorias de usuários e faixas de consumo, permitindo que os usuários mais ricos subsidiassem aqueles mais pobres (subsídio cruzado) e mesmo assim mantivesse uma tarifa média suficiente para sustentar o equilíbrio financeiro das companhias de saneamento. ${ }^{15}$

A partir de 1988 ocorre uma desregulamentação tarifária com a extinção do BNH e com a revogação da legislação até então vigente. Num quadro de aguda aceleração inflacionária, algumas CESBs conseguiram fixar tarifas quase livremente, sem qualquer tipo de regulamentação ou controle externo. Esse processo de desregulamentação foi conduzido mediante avanços e retrocessos, até que em 1991 o novo Ministério da Economia, Fazenda e Planejamento formalizou a transferência da responsabilidade pelo controle das tarifas ao poder concedente. Assim sendo, no âmbito das CESBs essa

13 Cada CESB (Companhia Estadual de Saneamento Básico) possuía critérios próprios para definição de sua tarifa, a partir das orientações estabelecidas pelo BNH - Banco Nacional de Habitação. Em alguns casos, o reajuste era submetido ao Conselho Interministerial de Preços (CIP) e, em outros, aos governos estaduais. (SILVA, 1995a, p. 153 e SILVA, 1995b, p. 319).

14 As tarifas deveriam ser calculadas de modo a cobrir os custos dos serviços e remunerar em até $12 \%$ do investimento. Este resultado garantiria a expansão do sistema e a manutenção dos índices de atendimento já existentes. As tarifas seriam reajustadas anualmente com base nos estudos realizados pelas companhias, sendo, em seguida, avaliadas pelo Ministério do Interior/BNH e submetidas ao CIP do Ministério da Fazenda, que autorizava ou não os reajustes tarifários. (SILVA, 1995a, p. 322 e HOLANDA, 1995, p. 59).

15 As categorias de consumo compreendiam a residencial, comercial, industrial e pública. Na categoria residencial, as tarifas deveriam ser (de acordo com a Lei) diferenciadas para as diversas faixas de consumo e deveriam ser progressivas em relação ao volume faturado. Para os usuários das categorias comercial e industrial deveria haver duas tarifas específicas: uma referente ao volume mínimo e outra ao excedente, sendo que a segunda seria superior à primeira e esta maior que a tarifa média. A lei admitia ainda a existência de tarifas especiais para grandes usuários comerciais e industriais, bem como para usuários temporários. (HOLANDA, 1995, p. 58). 
responsabilidade coube aos governos estaduais, sendo que alguns deles assumiram uma política tarifária voltada para o equilíbrio econômico-financeiro da companhia.

Desde então, até os dias atuais, as tarifas dos serviços de água e esgoto são determinadas sem uma legislação específica e de maneira descentralizada pelas CESBs, pelos prestadores de abrangência regional, bem como pelos serviços autônomos dos municípios (prestadores de abrangência local). A Tabela 4 mostra uma comparação entre as tarifas e as despesas médias praticadas no ano de 1999. Tomando-se no agregado, a margem líquida média (tarifa menos despesas) dos 174 prestadores de serviços analisados foi da ordem de R $\$ 0,01 / \mathrm{m}^{3}$, e em $36 \%$ dos casos estes serviços ficaram deficitários.

\section{TABELA 4 - ESTATÍSTICAS DAS DESPESAS, TARIFAS E MARGEM LÍQUIDA NOS SERVIÇOS DE ÁGUA E ESGOTO, SEGUNDO O TIPO DE PRESTADOR DE SERVIÇOS E NO AGREGADO - ANO DE REFERENCIA: 1999}

\begin{tabular}{|c|c|c|c|c|c|}
\hline \multirow[t]{3}{*}{ Estatísticas } & \multicolumn{5}{|c|}{ Serviços por área de abrangência } \\
\hline & \multirow[t]{2}{*}{ Unidade } & \multirow{2}{*}{$\begin{array}{l}\text { Regional } \\
\text { CESBs }\end{array}$} & \multicolumn{2}{|c|}{ Microrregional e local } & \multirow[t]{2}{*}{ Total } \\
\hline & & & Públicos & Privados $^{4}$ & \\
\hline 1- Quantidade de prestadores & u.d. & 27 & 130 & 17 & 174 \\
\hline \multicolumn{6}{|l|}{2 - Despesas ${ }^{1}$} \\
\hline Média & $\mathrm{R} \$ / \mathrm{m}^{3}$ & 1,29 & 0,57 & 0,55 & 0,64 \\
\hline Máx. & $\mathrm{R} \$ / \mathrm{m}^{3}$ & 3,02 & 1,47 & 0,93 & 3,02 \\
\hline Mín. & $\mathrm{R} \$ / \mathrm{m}^{3}$ & 0,60 & 0,47 & 0,08 & 0,04 \\
\hline \multicolumn{6}{|l|}{3 -Tarifas ${ }^{2}$} \\
\hline Média & $\mathrm{R} \$ / \mathrm{m}^{3}$ & 0,98 & 0,60 & 0,57 & 0,66 \\
\hline Máx. & $\mathrm{R} \$ / \mathrm{m}^{3}$ & 1,69 & 1,24 & 0,92 & 1,69 \\
\hline Mín. & $\mathrm{R} \$ / \mathrm{m}^{3}$ & 0,63 & 0,01 & 0,29 & 0,01 \\
\hline \multicolumn{6}{|l|}{4 - Margem Líquida ${ }^{3}$} \\
\hline Média & $\mathrm{R} \$ / \mathrm{m}^{3}$ & $-0,30$ & 0,08 & 0,01 & 0,01 \\
\hline Mediana & $\mathrm{R} \$ / \mathrm{m}^{3}$ & $-0,18$ & 0,07 & 0,00 & 0,04 \\
\hline Máx. & $\mathrm{R} \$ / \mathrm{m}^{3}$ & 0,30 & 0,61 & 0,26 & 0,61 \\
\hline Mín. & $\mathrm{R} \$ / \mathrm{m}^{3}$ & $-2,16$ & $-0,26$ & $-0,28$ & $-2,16$ \\
\hline Desvio padrão & $\mathrm{R} \$ / \mathrm{m}^{3}$ & 0,52 & 0,14 & 0,15 & 0,28 \\
\hline Proporção de déficits & $\%$ & 70 & 30 & 47 & 36 \\
\hline
\end{tabular}

Fonte: Estatísticas calculadas com base nos dados do Diagnóstico dos Serviços de Água e Esgoto $1999 /$ SNIS.

(1) Despesas com o serviço por $\mathrm{m}^{3}$ faturado: inclui as despesas de exploração, juros e encargos, depreciação, amortização e provisão para devedores duvidosos, entre outras. (2) Tarifa média praticada por $\mathrm{m}^{3}$ faturado: inclui os serviços de água, esgoto e venda de água por atacado. (3) Diferença entre a tarifa e a despesa média. (4) Serviços que estão sob concessão de empresas privadas. Fonte: ABCON - Associação Brasileira das Concessionárias de Serviços Públicos de Água e Esgoto. Situação atualizada em setembro/2001. Estão incluídos os serviços que tiveram data inicial de operaçấo em 1999 ou antes e participaram do SNIS 1999. 
Os melhores indicadores referem-se aos serviços públicos oferecidos pelos próprios municípios, onde se destacam os Serviços Autônomos de Água e Esgoto e os serviços ofertados diretamente por meio de algum dos departamentos das prefeituras. Em média, esses serviços obtiveram a maior margem líquida (R\$ $\left.0,08 / \mathrm{m}^{3}\right)$ do setor, sendo que apenas $30 \%$ dos casos permaneceram deficitários. Já os serviços concedidos ao setor privado, embora obtivessem uma margem líquida média positiva no conjunto, cerca de $50 \%$ deles não conseguiram cobrir todas as despesas de provisão de água e de esgotamento sanitário.

A pior situação constatada no ano de 1999 foi das companhias estaduais de abastecimento. Em 70\% dos casos as tarifas não foram suficientes para pagar os custos dos serviços e, em média, as companhias levaram um prejuízo de $\mathrm{R} \$ 0,30 / \mathrm{m}^{3}$. Entretanto, a prática tarifária das companhias estaduais (CESBs) é a mais heterogênea entre os grupos. ${ }^{16}$ Por mais que as companhias estaduais tenham reajustado suas tarifas, não têm conseguido repor o índice de crescimento das despesas. A evidência mais clara do Equilíbrio de Baixo Nível é confirmada pelos dados que mostram (ver Tabela D do anexo) praticamente a metade das CESBs reajustando suas tarifas numa proporção inferior ao índice de aumento das despesas. Considerando o grupo das 27 companhias, as tarifas foram reajustadas em torno de $57 \%$ no período de 1995 a 1999 , enquanto as despesas aumentaram em $63 \%$ no mesmo período. ${ }^{17}$

Uma decorrência imediata desses déficits tarifários é que a maior parte da tarifa cobrada é destinada ao pagamento de salários, restando pouco para que o setor possa investir na expansão e na melhoria dos serviços de forma autônoma. Com raras exceções, as margens de despesas com pessoal em relação à receita operacional são muito elevadas. De acordo com os dados da Tabela 5, apenas 5 prestadores de serviços (dentre 192 casos analisados) gastaram menos do que $20 \%$ da receita operacional com pessoal, indicador esse que tem sido atingido com certa facilidade no Chile. (SPILLER \& SAVEDOFF, 1999, p. 16). Dentre estes prestadores de serviços estão a Companhia Estadual de Saneamento do Estado de Tocantins (SANEATINS), a concessionária privada que presta os serviços para o município de Salto, no Estado de São Paulo, bem como outros três prestadores de serviços municipais. ${ }^{18}$

16 A Tabela C do anexo apresenta uma série de 1995 a 1999 para o caso específico dessas companhias, de onde se constata que a SABESP (no Estado de São Paulo) e a SANEPAR (no Estado do Paraná) ficaram superavitárias em todo o período. Em contraste, as Companhias das Regiôes Norte, Nordeste e CentroOeste apresentaram déficits persistentes ao longo do período.

17 Algumas companhias, como a SANEMAT no Mato Grosso e a CAEMA no Maranhão, chegaram a acumular diferenças de $145 \%$ e $266 \%$, respectivamente, entre seus reajustes tarifários e o aumento das despesas no período.

18 Os dados estão detalhados na Tabela $\mathrm{E}$ do anexo. 
De modo geral, as concessionárias privadas que prestam os serviços municipais são as que menos gastam com pessoal: $50 \%$ delas gastam $49 \%$ ou menos da receita operacional com o pagamento de pessoal. No caso das CESBs, a metade delas gastou $56,6 \%$ ou mais com pessoal. ${ }^{19}$ Mas a pior situação, nesses termos, foi a dos serviços municipais públicos (Serviços Autônomos de Água e Esgoto, Departamentos etc.), já que a metade deles gastou $58,4 \%$ ou mais da receita operacional apenas com pessoal. Os municípios de São Gonçalo do Amarante (no Rio Grande do Norte), de Jerônimo Monteiro (no Espírito Santo), de Araguari e de Ipanema (em Minas Gerais) gastaram, com pessoal, quantias bem acima da receita operacional arrecadada com os serviços de água e esgoto.

Outra decorrência natural dos déficits tarifários é, como já foi dito, a limitação da capacidade do setor de se autofinanciar. Os investimentos por meio de recursos próprios ficam limitados, e cada vez mais o setor passa a depender das transferências governamentais. Historicamente, no Brasil, os programas de saneamento básico têm sido financiados por meio de três fontes de recursos: i) orçamentos fiscais da União, Estados, Distrito Federal e municípios; ii) recursos do Fundo de Garantia do Tempo de Serviço (FGTS); iii) de empréstimos internos e externos. Segundo Silva (1995b, p. 163), os recursos do Orçamento Geral da União (OGU) são aplicados mediante dotações a diversos ministérios, que os transferem para outros órgãos da própria administração federal, como a Fundação Nacional de Saúde e, no passado, o BNH.

As aplicações dos estados e municípios são realizadas pelas secretarias e outros órgãos da administração direta ou mediante transferências dos governos aos Fundos de Água e Esgoto (FAES) ou às Companhias Estaduais de Saneamento Básico (CESBs). Nos últimos anos, estados e municípios também têm conseguido acesso aos empréstimos externos de agências multilaterais de crédito, tais como o Banco Mundial (BIRD), o Banco Interamericano de Desenvolvimento (BID), o instituto alemão Kreditanstalt für Wiederausban (KFM) e o fundo japonês Overseas Economic Cooperation Fund (OECF). (SILVA, 1995b, p. 163 e RESENDE et alii, 1995, p. 156).

Mas a principal fonte de recursos para o financiamento do setor, pelo menos até o início da década de 1990, foi o Fundo de Garantia por Tempo de Serviço (FGTS). ${ }^{20}$ A partir de 1969, parcelas significativas desse fundo passaram a ser aplicadas também em programas de saneamento. No entanto, como demonstraram Rezende et alii (1995) e Silva (1995b), a partir do final dos anos 1980 o FGTS perde gradualmente a sua capacidade de aplicação de recursos e, em particular, no setor de saneamento. Este fato se

19 Sendo que a SANEMAT (no Mato Grosso) e a DEAS (no Acre) chegaram a gastar muito acima do que foi arrecadado em termos de receita operacional.

20 Este fundo foi instituído em 1966 com o intuito de corrigir algumas distorçôes no mercado de trabalho e alavancar recursos para financiar o setor habitacional. 
deve a um efeito combinado da estagnação da arrecadação bruta e do crescimento dos saques do fundo, produzindo uma queda na arrecadação líquida.

\section{TABELA 5 - DISTRIBUIÇÃO DE FREQÜÊNCIAS DAS MARGENS DE DESPE- SAS COM PESSOAL, SEGUNDO O TIPO DE PRESTADOR DE SERVIÇOS - ANO DE REFERENCIA: 1999}

\begin{tabular}{|c|c|c|c|c|}
\hline \multirow{3}{*}{$\begin{array}{l}\text { Margens de } \\
\text { Despesas }{ }^{1} \\
\% \text { em classes }\end{array}$} & \multirow{3}{*}{$\begin{array}{c}\text { Freqüência } \\
\text { Total } \\
\text { Quant. }\end{array}$} & \multicolumn{3}{|c|}{ Frequêência por tipo de prestador } \\
\hline & & \multirow{2}{*}{$\begin{array}{l}\text { Estaduais } \\
\text { CESBs }\end{array}$} & \multicolumn{2}{|c|}{ Municipais $^{2}$} \\
\hline & & & Públicos & Privados $^{3}$ \\
\hline (10 |----- 20 & 5 & 1 & 3 & 1 \\
\hline $20 \mid-----30$ & 9 & 1 & 6 & 2 \\
\hline 30 |------ 40 & 18 & 1 & 13 & 4 \\
\hline $40 \mid-----50$ & 33 & 4 & 26 & 3 \\
\hline 50 |----- 60 & 39 & 9 & 28 & 2 \\
\hline $60 \mid-----70$ & 36 & 5 & 28 & 3 \\
\hline 70 |------ 80 & 24 & 3 & 20 & 1 \\
\hline $80 \mid-----90$ & 16 & 1 & 14 & 1 \\
\hline 90 |----- 100 & 6 & - & 6 & - \\
\hline 100 ou mais & 6 & 2 & 4 & - \\
\hline Total & 192 & 27 & 148 & 17 \\
\hline
\end{tabular}

Fonte: Diagnóstico dos Serviços de Água e Esgoto - 1999/SNIS.

(1) Porcentual das despesas com pessoal próprio e com terceiros em relação à receita operacional direta com água e esgoto. (2) Incluem os serviços de abrangência regional e local. (3) Concessionárias privadas. Fonte: ABCON - Associação Brasileira das Concessionárias de Serviços Públicos de Água e Esgoto. Situação atualizada em setembro/2001. Estão relacionados aqueles serviços que tiveram data inicial de operação em 1999 ou antes e participaram do SNIS 1999.

A aplicação do FGTS no setor de saneamento foi realizada essencialmente por meio dos dois principais programas governamentais para o setor: a Política Nacional de Saneamento - Planasa ( 1971/89) e o Programa de Saneamento para Núcleos Urbanos Pronurb (a partir de 1990). ${ }^{21}$ No entanto, o volume total de recursos aplicados por esses programas segue uma trajetória decrescente a partir do final dos anos 1980, depois de ter recuperado no período de 1984/1988, como mostra a Figura 2. Em contrapartida, as aplicaçôes do governo federal, por meio do Orçamento Geral da União (OGU), aumentaram gradualmente nesse período, sendo que em 1992 já ultrapassara o valor dos empréstimos no âmbito do Pronurb.

21 A Tabela F do anexo mostra a crescente participação do FGTS dentre as fontes de recursos utilizadas por esses programas nas últimas décadas. 


\section{FIGURA 2 - INVESTIMENTOS EM SANEAMENTO BÁSICO COM RECURSOS DO PLANASA/PRONURB E DO OGU - 1980/93}

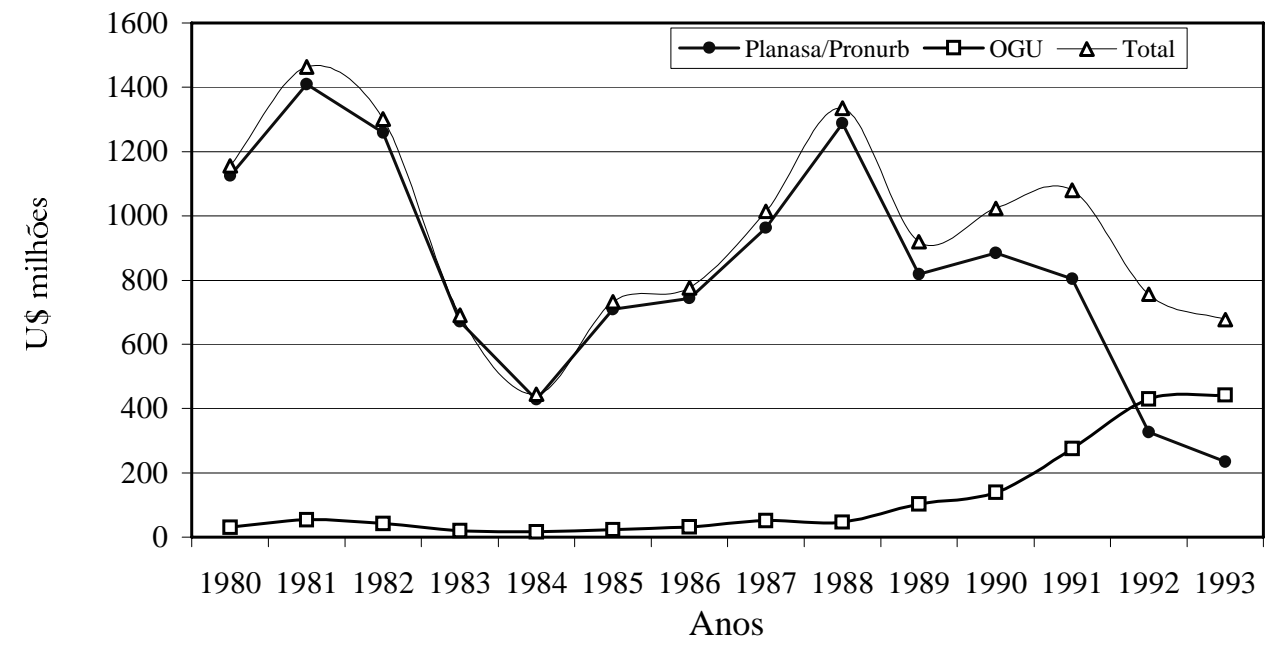

Fonte: Elaborado com base em SILVA (1995b) e REZENDE et alii (1995), a partir de dados do Balanço Geral da União e da CEF/BNH. (1) Planasa em 1980/89 e Pronurb a partir de 1990. (2) OGU - Investimentos realizados pelo Tesouro Nacional nos subprogramas Abastecimento de Água, Saneamento Geral e Sistemas de Esgoto.

No período mais recente, estas séries não foram disponibilizadas. Mas com a base de dados do SNIS é possível verificar a evolução dos investimentos das Companhias Estaduais de Saneamento durante o período de 1995/1999. A Figura 3 mostra um crescimento nos investimentos em água e esgoto no período 1995/1998 e uma queda no ano de $1999 .^{22}$ Infelizmente estas séries não foram geradas segundo a fonte de recursos, o que dificulta a comparação com o período anterior.

Entretanto, para o ano de 1999, as informações do SNIS permitem comparar os investimentos em termos de recursos próprios, de recursos onerosos e de não onerosos. ${ }^{23}$ Dos R 2,4 bilhões investidos no ano de 1999 por 193 prestadores de serviços em todo o Brasil, 9,2\% foram originados de fontes não onerosas. ${ }^{24}$ Comparando esse por-

22 A queda referente ao ano de 1999 não foi tão abrupta quanto aparece na Figura. Esta queda está superestimada devido à conversão para a moeda norte-americana, já que em 1999 há uma elevação do preço do dólar e uma mudança do regime cambial. Para suavizar esse efeito da taxa de câmbio, os investimentos realizados em 1999 foram convertidos pela taxa de câmbio média do mês de janeiro, antes da mudança do regime cambial.

23 Os recursos onerosos são aqueles provenientes de qualquer fonte, mas que foram realizados mediante financiamentos reembolsáveis por meio de amortizações, juros e outros encargos. Já os recursos não onerosos são empréstimos a fundo perdido e podem servir como uma aproximação das transferências governamentais (federal, estaduais e municipais) para o setor.

24 Ver os dados da Tabela G do anexo. 
centual com a participação dos recursos fiscais na primeira metade nos anos 1990, tudo indica que o setor público reduziu suas aplicações a fundo perdido no setor. Não obstante, elas ainda continuam sendo significativas.

FIGURA 3 - INVESTIMENTOS EM ABASTECIMENTO DE ÁGUA E EM ESGOTO $-1995 / 99$

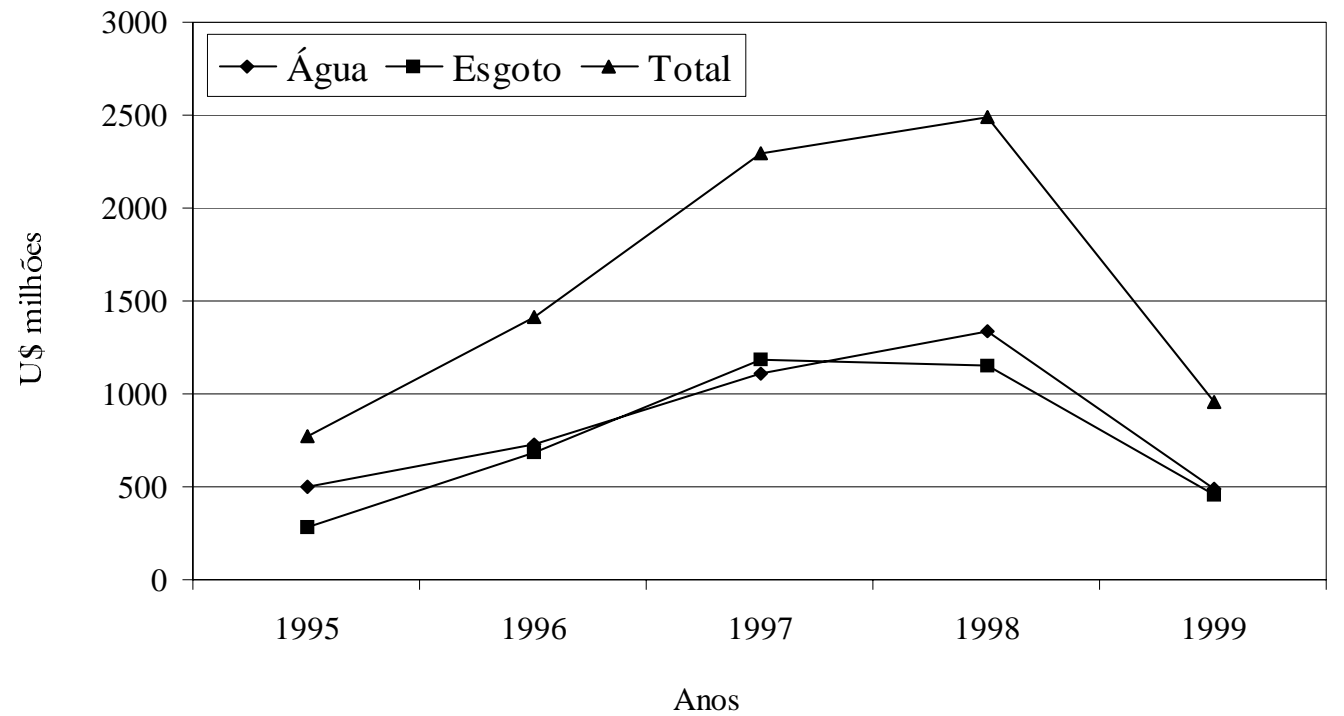

Fonte: Elaborado com base nos dados dos Diagnósticos dos Serviços de Água e Esgoto - 1995/99 SNIS. Os valores em R\$ foram convertidos em US pela taxa de câmbio média anual. Os valores referentes ao ano de 1999 foram convertidos pela taxa de câmbio média do mês de janeiro deste ano.

\subsection{O Arranjo Institucional no Setor de Saneamento e o Oportunismo do Governo}

Dois aspectos marcantes no setor de oferta de serviços de água e saneamento brasileiro foram destacados em nossa análise: a baixa qualidade dos serviços de saneamento e uma prática tarifária incapaz de cobrir os custos dos serviços. A correlação entre estes dois fatos é clara: quanto menor a capacidade das tarifas cobrirem os custos dos serviços, maior a probabilidade de tais serviços não atingirem os níveis desejáveis de qualidade, uma vez que os investimentos no setor ficam comprometidos. É menos claro, no entanto, o porquê de uma prática tarifária inadequada. A explicação de Spiller e Savedoff (1999) é sensata. Dependendo do arranjo institucional, cria-se a oportunidade para o governo interferir na política de preços. Essa oportunidade é aproveitada principalmente nas condições em que os serviços são de posse pública, quando existe instabilidade política e quando não existe suporte político para os reajustes necessários das tarifas. 
A posse pública, por si só, não é a condicionante fundamental para a existência de um EBN. Um ponto bastante consensual na literatura sobre regulação de monopólios naturais é que se a posse é privada, e não existe um modelo adequado de regulação, os resultados podem ser até piores em termos de perdas de bem-estar social. Fica claro, então, que mais relevante do que a posse pública, o ponto focal está no modelo de gestão, particularmente na sua capacidade de regulação oferecida pelo arranjo institucional. ${ }^{25}$ Não obstante, no caso brasileiro, esta é uma condição propícia para intervenção governamental, uma vez que a participação do setor privado nos serviços de saneamento é mínima. ${ }^{26}$

A instabilidade política, por outro lado, é uma explicação parcialmente verdadeira para o caso brasileiro. A argumentação de Spiller e Savedoff (1999) é de que, na presença de instabilidade política no País, não haverá capital privado interessado em investir no setor, por mais que essa estratégia faça parte dos planos do governo. Diante disso, o governo não consegue se eximir da responsabilidade de operar diretamente o setor. Entretanto, ainda que exista um "Risco Brasil" não desprezível, a participação do setor privado no processo de privatização do País tem sido significativa. No âmbito do PND - Plano Nacional de Desestatização - a participação do capital estrangeiro também tem sido significativa, principalmente no setor elétrico e telecomunicações. ${ }^{27}$

Então, se existe desinteresse do capital privado pelo setor de saneamento, certamente isso não se deve à instabilidade política do País. Esta hipótese é mais realista para o caso brasileiro se a instabilidade for tratada dentro do setor de saneamento em particular, uma vez que o arranjo institucional e as leis vigentes não fornecem as condições de segurança necessárias ao capital privado. Como demonstraram Muller e Pereira (2001), o desenho das agências de regulação no Brasil é determinado por um trade-off existente entre o benefício do ganho de credibilidade do governo e o custo da perda do controle sobre os serviços. No caso específico do setor de saneamento, o custo da perda do controle parece superar os benefícios da credibilidade a ponto de nem existir uma motivação suficientemente forte para a criação de uma agência de regulação autônoma. $^{28}$

25 Na realidade, esse entendimento é compartilhado também por SPILLER \& SAVEDOFF (1999).

26 A Tabela $\mathrm{H}$ do anexo relaciona os 35 consórcios privados existentes e que atualmente operam os serviços de água e esgoto em 55 municípios. Considerando que existem 5.507 municípios no País, a participação do setor privado não chega atingir $1 \%$ dos serviços.

27 Os dados da Tabela I do anexo confirmam esta afirmativa: cerca de 60\% dos investimentos no setor de Telecomunicações são provenientes de empresas estrangeiras, especialmente dos EUA, Espanha, Portugal e Itália. Nos demais setores, bem como nas privatizaçốes estaduais, a participação também é expressiva: $35,9 \%$ e $48,9 \%$, respectivamente.

28 Outra particularidade no setor de saneamento é que a grande maioria dos municípios firmou contratos com as Companhias Estaduais de Saneamento, sendo que muitos deles vencerão depois do ano de 2010. 


\section{O Arranjo Institucional Vigente e sua Evolução Recente}

Como foi dito anteriormente, dependendo do arranjo institucional, cria-se a oportunidade para o governo interferir na política de preços, o que muitas vezes é feita de forma inadequada. Então, quais são as condiçôes necessárias para o setor sair do Equilíbrio de Baixo Nível? De acordo com Spiller e Savedoff (1999) é necessário algum arranjo institucional que dê maior autonomia financeira e gerencial à operadora $\mathrm{e}$ restrinja a influência política no processo de reajuste tarifário. Isso naturalmente requer um sistema regulatório que inclua não só uma agência autônoma de regulação para o setor, mas também algumas regras clássicas defendidas pela teoria da regulação, tal como clareza nas restriçôes mais importantes para operar o sistema de abastecimento d'água.

No Brasil, ao longo dos últimos anos, uma grande quantidade de mudanças institucionais ocorreu no setor de saneamento, sem que no entanto atacasse aqueles pontos. Nesta subseção apresentamos uma síntese das principais mudanças institucionais ocorridas no setor de saneamento no Brasil.

A história política do setor, da segunda metade do século passado até 1994, é abordada por Silva (1995b) e Emerciano e Baltar (1995). Até o início da década de 1930, os serviços de saneamento eram prestados dentro de um modelo institucional e financeiro bastante flexível. O governo delegava os serviços de abastecimento de água e de esgotamento sanitário às empresas estrangeiras via concessão pública. As tarifas cobriam os custos e remuneravam o capital investido e muitas vezes o governo garantia uma rentabilidade mínima às concessionárias.

A partir de meados da década de 1930, o Estado elevou sua participação nos serviços básicos e interveio mais fortemente na economia, por meio de regulamentaçôes, controle de preços, produção de insumos básicos etc. Aos poucos as empresas concessionárias estrangeiras foram estatizadas e os serviços de saneamento foram assumidos pelas prefeituras municipais, por meio de departamentos ou serviços autônomos de água e esgoto. Na década de 1960 foram tomadas importantes medidas que moldariam a formulação de políticas explícitas posteriores para o setor. Entre elas destacaram-se a criação do Banco Nacional de Habitação (BNH), do Fundo de Garantia por Tempo de Serviço (FGTS) e o Decreto Lei n. ${ }^{\circ}$ 200/67. ${ }^{29}$

29 O BNH, por muito tempo, passou a ser o órgão gestor, executor e financiador do setor de saneamento. O FGTS se tornou, posteriormente, a principal fonte de recursos para financiamento do setor. O Decreto n. ${ }^{\circ}$ 200/67 delegou ao Ministério do Interior, por meio do BNH, a responsabilidade de formular e implementar a política nacional para o setor, que até então era conduzida por diversos órgãos federais, sem nenhum controle ou diretrizes preestabelecidas. 
Em 1969, o Banco Nacional de Habitação (BNH) ficou autorizado a aplicar parcela do FGTS em programas de saneamento, além de seus próprios recursos. A utilização dos recursos do FGTS viabilizou o Sistema e permitiu a criação de diversos programas de financiamento e de instrumentos de gestão para o setor. Merece destaque o estímulo à criação das Companhias Estaduais de Saneamento Básico (CESBs), como principais agentes operadores dos serviços de água e esgoto, constituindo-se, até hoje, no mais importante componente operacional da estrutura do setor. Em 1971, o BNH instituiu a Política Nacional de Saneamento (Planasa), delimitando o início de um novo período para o setor. Além de atuar de forma planejada e coordenada, o Planasa fundamentou-se num conjunto de objetivos e princípios que nortearam a política nos anos subseqüentes. ${ }^{30}$

O arranjo institucional do Planasa envolvia, pelo menos na sua origem, um conjunto de órgãos e instituições, governamentais ou não, tais como $\mathrm{BNH}$, governos estaduais, CESBs, agentes financeiros, órgãos gestores, órgãos técnicos, empresas privadas e governos municipais. O BNH era o responsável pela gestão do Sistema e tinha atribuições de normatização, coordenação e aprovação dos programas estaduais e da política tarifária das CESBs. Os governos estaduais teriam a responsabilidade de constituir e de manter o controle acionário das companhias. Estas, por sua vez, constituíam a base operacional de todo o sistema e prestavam os serviços na esfera estadual, a partir da concessão recebida dos municípios. Aos governos municipais competia conceder a exploração dos serviços às CESBs. ${ }^{31}$

A partir de meados da década de 1980, no entanto, inaugura-se uma longa e prolongada crise institucional do setor. Em 1996, o BNH é incorporado pela Caixa Econômica Federal (CEF). O final dos anos 1980 e o início dos anos 1990 são marcados por uma série de mudanças administrativas (ministeriais) no âmbito federal, que foram, na melhor das hipóteses, inócuas para o setor de saneamento. A formulação das políticas urbanas ficou a cargo de vários ministérios e, sendo conduzida de forma descoordenada, agravou a crise iniciada no começo da década. Em 1992, o Planasa foi extinto e todas as linhas de crédito desse Plano foram unificadas em um novo programa denominado Pronurb - Programa de Saneamento para Núcleos Urbanos.

O Pronurb passou a ser gerido pelo Ministério da Ação Social (MAS), e a Caixa Econômica Federal seria o agente operador, sendo que os governos estaduais, prefeituras municipais, serviços autônomos municipais e companhias estaduais seriam os agentes promotores. No entanto, em razão da generalizada inadimplência, tanto dos estados

30 Entre eles destacam-se a busca pela auto-sustentação financeira do setor de saneamento, o desenvolvimento institucional das companhias estaduais e a instituição de uma política tarifária com vistas a pagar os serviços e a remuneração do capital, além de permitir os subsídios cruzados.

31 As empresas privadas tinham apenas uma participação indireta, sendo encarregadas de elaborar projetos de engenharia, construir obras, produzir equipamentos e materiais. 
quanto das CESBs, do baixo retorno dos empréstimos contratados e da redução da arrecadação líquida do FGTS, o Pronurb encontrou dificuldades em promover investimentos compatíveis com o crescimento populacional e a necessidade de reduzir os déficits existentes. (SILVA, 1999b, p. 160). ${ }^{32}$

A partir de 1995, inicia-se uma nova fase política no setor, caracterizada pela busca de um novo padrão de intervenção do Estado. ${ }^{33}$ A Constituição Federal de 1988 e a aprovação da Lei das Concessóes (Lei 8.987/95) abrem novas perspectivas de mudanças e amplia o espaço à flexibilização de prestação de serviços públicos. ${ }^{34}$ É nesse contexto de mudança do padrão de intervenção do Estado que surge a Nova Política Nacional de Saneamento. Seu princípio básico está na intenção da União em atuar, sobretudo, como reguladora, articuladora e promotora das questões relacionadas às políticas de saneamento.

Entretanto, a formulação e a concretização de um novo modelo institucional para a Política Nacional de Saneamento requer, ainda, instrumentos jurídicos-legais e normativos. Dentre eles, o próprio documento de intenções da SEDU destaca: ${ }^{35}$ i) necessidade de uma lei que trate da cooperação entre as esferas do governo e entre estas e a sociedade, no âmbito das competências comuns em matéria de saneamento; ii) um conjunto de instrumentos que disponha sobre a criação e o funcionamento de um sistema de financiamento e gestão de recursos da União para aplicações em saneamento; iii) legislação específica para regular as empresas prestadoras de serviços de saneamento; iv) normas e regulamentos referentes às relações contratuais para prestação dos serviços; e v) revisão dos mecanismos tarifários e de subsídios.

32 Para mais detalhes dessas mudanças institucionais no período, veja SILVA (1995b).

33 Esse período não foi analisado por SILVA (1995b). No início, a responsabilidade da política de saneamento ficou a cargo da Secretaria de Política Urbana - SEPURB - no âmbito do Ministério do Planejamento, que mais tarde, em 1999, foi transformada na atual Secretaria Especial de Desenvolvimento Urbano SEDU, vinculada diretamente à Presidência da República. Atualmente, além da SEDU, diversos órgãos federais atuam no setor: Ministério da Saúde (principalmente por meio da FUNASA - Fundação Nacional da Saúde), Ministério do Meio Ambiente, Recursos Hídricos e Amazônia Legal (por meio da ANA Agência Nacional das Águas) e Caixa Econômica Federal - CEF (como agente financeiro). Além de coordenar e articular as ações e programas desses ministérios, a SEDU tem a incumbência de promover a parceria com estados, municípios e com o setor privado.

34 A Constituição Federal de 1988 passa a delinear o modelo de gestão nos anos subseqüentes e constitui-se, atualmente, numa das principais referências para qualquer pretensão em termos de reordenamento institucional. Trata-se da primeira constituição brasileira a dedicar um capítulo à política urbana, sendo que diversos dispositivos são relacionados especificamente ao setor de saneamento. O primeiro ponto de relevante interesse é que o setor de saneamento é reconhecido como sendo de competência local, cabendo aos municípios prestar tais serviços, diretamente ou sob regime de concessão ou permissão (Art. 30). No entanto, o Art. 21 estabelece que a União é responsável pelo papel de instituir diretrizes para o desenvolvimento urbano, inclusive habitação e saneamento básico. Ainda no texto constitucional, o Art. 23 diz que é competência comum da União, dos estados, do Distrito Federal e dos municípios promover programas de construção de moradia e a melhoria das condições habitacionais e de saneamento básico. Essa falta de clareza no texto constitucional, em termos das competências entre as esferas do governo, tem dificultado o reordenamento do setor.

35 PNS - Política Nacional de Saneamento/SEDU - Secretaria de Desenvolvimento Urbano. 
Em fevereiro de 2001, o Poder Executivo encaminhou ao Congresso Nacional o Projeto de Lei n. ${ }^{\circ}$ 147/2001 que institui diretrizes nacionais para o saneamento, entre outras providências. As diversas matérias tratadas neste Projeto de Lei regulamentam praticamente todas as pendências acima citadas. Além do mais, prevê que a prestação dos serviços de saneamento básico será organizada com base em bacias hidrográficas (Art. $3^{\circ}$ ), o que harmoniza a política do setor com a Política Nacional de Recursos Hídricos. Outro aspecto importante do referido Projeto é que os serviços de saneamento básico deverão ser regulados e fiscalizados por entidade de direito público, exceto quando prestados diretamente por órgão ou entidade de direito público do próprio titular $\left(\right.$ Art. $\left.11^{\circ}\right)$. Além do mais, as entidades responsáveis pela regulação deverão ter autonomia administrativa, financeira e técnica e serem credenciadas pela Agência Nacional de Águas - ANA.

O Projeto não prevê a criação de uma agência reguladora específica para o setor no âmbito nacional. Apenas estabelece que a Agência Nacional das Águas deve colaborar com a Secretaria Especial de Desenvolvimento - SEDU - no desenvolvimento das ações de saneamento básico e determina algumas atribuições específicas a esta agência. A idéia do Projeto é de que a regulação e a fiscalização sejam realizadas por entidades no âmbito local e estimuladas pelo titular dos serviços (municípios ou estados, quando tais serviços forem enquadrados como de interesse comum). ${ }^{36}$ Até o momento, no entanto, este Projeto de Lei ainda não foi votado pelo Congresso Nacional. A despeito dos motivos da não votação deste Projeto, tal fato deixa o setor numa situação de "vácuo" institucional, sem que haja qualquer regulamentação em nível federal no que diz respeito à Política Nacional de Saneamento e, em especial, às condiçôes de regulação e de fiscalização da prestação de serviços.

Então, do ponto de vista institucional, essa situação deixa o setor de saneamento em condições semelhantes àquelas que caracterizaram o desmantelamento do Planasa no início dos anos 1990. Na realidade, dentro da concepção do modelo do Equilíbrio de Baixo Nível, nada de substancial foi mudado, em nível do executivo federal, a ponto de efetivamente surtir efeitos, uma vez que as condiçôes de oportunismo na política tarifária permanecem as mesmas da década passada.

\section{A Falta de Suporte Político e Outros Fatores}

A falta de suporte político talvez seja a hipótese mais delicada de ser tratada na explicação de Spiller e Savedoff (1999). Por um lado, é uma condição fundamental da exis-

\footnotetext{
36 Esta municipalização dos aspectos institucionais requer, no mínimo, um apoio da União e dos estados para a modelagem de um sistema regulatório, já que a maior parte dos municípios não possui capacidade técnica suficiente para assumir esse papel. Esse apoio vem sendo oferecido pela União por meio do Programa de Modernização do Setor Saneamento - PMSS, o qual financia estudos e projetos relacionados com o componente institucional.
} 
tência do EBN, juntamente com o modelo institucional. Por outro lado, é a hipótese mais difícil de ser testada empiricamente. A idéia de relutância dos políticos em conceder reajustes tarifários por falta de suporte político é bastante intuitiva, principalmente se os políticos são considerados como agentes racionais e maximizadores de seu poder político. No entanto, uma decisão em não conceder reajustes por tal motivo pode não ser explícita, sendo tomada em nome de outras razões. Sobre esta questão, Silva (1995b, p. 325) afirma que em alguns casos os governos estaduais adotavam tarifas abaixo dos custos em nome de políticas sociais e muitas vezes sem transparência nos subsídios praticados.

A despeito da dificuldade de se verificar o grau de realismo da falta de suporte político, tal hipótese não pode ser descartada. Analisando a questão tarifária no período do Planasa, Silva (1995b, p. 154) faz a seguinte constatação: embora um dos princípios básicos do plano fosse a implementação de tarifas reais, ..."sua utilização como instrumento de controle da inflação ou moeda política, reajustando-se abaixo dos indices de inflação, foi um dos motivos dos problemas enfrentados pelo setor." (Negrito acrescentado). Na realidade, o estudo do caso brasileiro evidencia pelo menos duas particularidades importantes sobre este ponto.

A primeira delas é que a interferência política na prática tarifária ocorreu muitas vezes como instrumento de contenção do processo inflacionário, principalmente nos anos 1980. No período de 1986/1989 foram implementados vários planos econômicos com essa finalidade: Plano Cruzado I e II (1986), Plano Bresser (1987) e o Plano Verão (1989), todos eles com vida curta e com agravantes para o setor de saneamento. Silva (1995b, p. 323) é bastante enfático neste sentido: "as tarifas eram contidas pelo Ministério da Fazenda para evitar acelevação da inflação." Já no início dos anos 1980 havia uma desobediência crescente em relação à legislação tarifária por parte das CESBs, que contestavam, com os estados, a autoridade do BNH sobre essa matéria. Em 1983, o governo federal transfere, então, a responsabilidade pela fixação e pelos reajustes das tarifas aos estados. No entanto, o Ministério da Fazenda continuaria interferindo na política tarifária com vistas a controlar a inflação, ignorando a grande defasagem tarifária existente em praticamente todas as CESBs e mantendo as tarifas em níveis muito abaixo dos custos definidos pela legislação.

Outra particularidade que fica mais evidente no caso brasileiro é que a falta de suporte político está associada à própria renda: quanto menor a renda do usuário, maior será a probabilidade deste usuário representar alguma ameaça para o político numa situação de reajuste tarifário. Embora essa relação seja mais ou menos óbvia, é totalmente desconsiderada por Spiller e Savedoff (1999). Os estudos acerca do EBN têm sido realizados em países em desenvolvimento, cuja renda per capita em geral é muito baixa. No Brasil, embora isso também seja verdade, existem regiôes ricas e com níveis per capita 
de renda elevados. Nestas condições, os usuários não representam ameaça política simplesmente porque a tarifa foi reajustada. Muitas vezes sequer tomam conhecimento do fato. Na realidade, essa é a percepção do político. Segundo Silva (1995a, p. 324), "freqüentemente as estruturas tarifárias foram manipuladas com objetivos politicos, através da prática de reajustes tarifários diferenciados, por faixa de consumo ou tipo de consumidor. A vinculação das tarifas com o poder aquisitivo da população vem sendo feita de forma intuitiva e sem critérios explícitos.”

Essa vinculação da tarifa com a renda da população acaba por afetar os índices de qualidade dos serviços. A equação (1) mostra uma relação estimada entre o índice de abastecimento de água $(Y)$ e o PIB per capita $(X)$ de 26 estados. O $\mathrm{R}^{2}$ do modelo, o teste $t$ do coeficiente de $X$ (em parêntese) e o p-value confirmam como os índices de atendimento são determinados pelo PIB per capita do estado. ${ }^{37}$

$$
\begin{gathered}
Y_{i}=\underset{(13,693)}{65,5}+0,0030484 X_{i} \\
(2,944)
\end{gathered}
$$

$$
\begin{aligned}
& \text { Estatística F: } 8,670 \quad \text { P-value: } 0,007 \\
& \mathrm{R}^{2} \text { ajustado }=0,235
\end{aligned}
$$

A relação entre a riqueza de uma região e o nível de qualidade dos serviços pode se dar por duas vias. De um lado, independentemente dos aspectos políticos e institucionais, quanto menor a riqueza (PIB per capita) da região, menor a capacidade de geração de impostos e, portanto, do estado ou município financiar os serviços de utilidade pública. Por isso, é natural observar altos índices de atendimento em estados mais ricos como São Paulo, Minas Gerais e Paraná (nas regiões Sul e Sudeste), independentemente do modelo institucional adotado. Por outro lado, quanto menor a renda de uma família, menor será sua capacidade de assumir os aumentos necessários das tarifas. É exatamente nessa linha de raciocínio que o político pode atuar, implementando tarifas diferenciadas, subsídios cruzados ou evitando os reajustes tarifários para aquelas classes menos desfavorecidas.

A base de dados do SNIS/99, além de confirmar a importância da renda, permite avaliar a influência de outros fatores no nível de cobertura dos serviços para uma amostra de 540 municípios distribuídos em todo o País. Para captar tais fatores foi estimada a seguinte regressão:

37 Para o caso da equação (1), o índice de atendimento $Y$ é o porcentual de domicílios com água canalizada em rede geral, de acordo com a definição adotada pela PNAD do IBGE. A variável $X_{1}$ foi obtida a partir dos PIBs municipais de 1996 (último disponível) calculados pelo IPEA/IBGE e da contagem populacional de 1996. Como o índice de atendimento para o ano de 1996 não está disponibilizado, foi utilizado uma média dos índices referentes aos anos de 1992 e 1999, como apresentados na Tabela A do anexo. 


$$
\begin{aligned}
& Y_{i}=79,5+0,00114 X_{1}+0,035 X_{2}-0,0000105 X_{2}^{2}-1,19 X_{3}+16,7 X_{4}+2,18 X_{5} \\
& \begin{array}{lllll}
(59,4) & (4,990) \quad(2,708) \quad(-2,349) \quad(-9,189) & (7,937) & (0,414)
\end{array}
\end{aligned}
$$

$$
\begin{aligned}
& \text { Estatística F: } 33,779 \quad \text { P-value: } 0,000 \\
& \mathrm{R}^{2} \text { ajustado }=0,267
\end{aligned}
$$

Onde:

$Y_{i}$ é o índice de atendimento de água no município $i ; X_{1}$ é o PIB per capita do município $i ; X_{2}$ é o número de economias ativas (em mil unidades); $X_{3}$ é o índice de produtividade do município medido pelo número de empregados por mil ligaçóes ativas; $X_{4}$ é uma variável dummy tal que $X_{4}=1$ se o serviço for prestado por uma instituição pública do próprio município (ou microrregional) e $X_{4}=0 \mathrm{em}$ caso contrário; e $X_{5}=1$ se o serviço for prestado por uma empresa privada e $X_{5}=0$ em caso contrário. Nestes termos, a constante da equação captura o índice médio de atendimento das Companhias Estaduais de Saneamento (CESBs) supondo que todas as demais variáveis tenham valores iguais a zero. ${ }^{38}$

Como na equação (1), o PIB per capita municipal é significativo de acordo com o teste $t$ (os valores em parêntese correspondem ao teste $t$ do respectivo coeficiente). As variáveis $X_{2}$ e $X_{2}^{2}$ indicam a importância do número de economias ativas em relação aos índices de cobertura, sendo que tais índices aumentam com o número de economias ativas (coeficiente de $X_{2}$ ), mas a uma taxa decrescente (coeficiente de $X_{2}^{2}$ ). A derivada da equação (2) em relação a $X_{2}$ mostra que o ponto de máximo é obtido quando $X^{*}=1,6$ milhões economias ativas. Este indicador confirma a dificuldade que pode ser encontrada em regiões metropolitanas para manter seus índices de atendimento, já que nesses casos o número de economias ativas pode ultrapassar aquele que seria $o$ ponto de ótimo. O número de empregados por mil ligaçóes $\left(X_{3}\right)$, por sua vez, afeta negativamente os índices de atendimento de água. O coeficiente estimado para essa variável indica o quanto o setor pode se tornar menos eficiente com o aumento de um empregado por mil ligações de água.

38 A variável $X_{1}$ foi obtida a partir dos PIBs municipais de 1996 calculados pelo IPEA/IBGE e da contagem populacional de 1996. As variáveis $X_{2}, X_{3}, X_{4}, X_{5}$ e $Y$ foram obtidas dos dados desagregados por município do Diagnóstico dos Serviços de Agua e Esgoto de 1999 do SNIS. Alguns índices de atendimento de água $(Y)$ estavam inconsistentes e foram eliminados da amostra. Tal índice é calculado dividindose a população atendida com abastecimento de Água pela população urbana total do respectivo município, sendo diferente, portanto, daqueles índices obtidos pelo IBGE. A variável $X_{2}$, número de economias ativas, está em mil unidades, sendo que uma economia ativa representa qualquer comércio ou residência que contribuiu para o faturamento no último mês do ano de referência (1999). 
O ponto mais importante captado pela equação (2) refere-se à comparação entre os níveis de atendimento das CESBs, dos serviços municipais e daqueles oferecidos por empresas privadas sob concessão. A constante da regressão mostra que o índice médio de cobertura de água nos municípios atendidos pelas CESBs é de 79,5\% quando as demais variáveis são desconsideradas (iguais a zero). Mas quando estes serviços são prestados diretamente pelo município (ou por uma instituição pública de âmbito microrregional), a dummy $X_{4}$ indica que os índices de cobertura aumentam em 16,7\% quando comparados com aqueles das CESBs. No entanto, quando os serviços são prestados por empresas privadas, o teste $t$ mostra que o coeficiente da dummy $X_{5}$ não é significativo, não permitindo, portanto, concluir se houve melhoras nos serviços em relação aos índices alcançados pelas Companhias Estaduais de Saneamento.

Este resultado, de certa forma, assemelha-se àqueles encontrados nos estudos sobre o Equilíbrio de Baixo Nível em outros países. Ou seja, em geral, a municipalização dos serviços produz resultados mais satisfatórios do que aqueles sistemas centralizados e fornecidos por grandes companhias de abastecimento. Além do mais, os poucos casos de concessão ao setor privado parecem seguir aquelas mesmas estratégias falhas adotadas em outros países, já que não existe um sistema adequado de regulação e de fiscalização e boa parte dos serviços são concedidos mediante simples contratos do tipo BOTs. No entanto, a situação dos serviços sob concessão privada merece uma investigação específica e uma análise mais detalhada de cada um dos contratos firmados entre município e operadora, os quais não foram disponibilizados para este estudo. Há que se considerar também que na maior parte dos casos de concessão não decorreu um tempo suficiente para avaliar a melhora dos serviços de saneamento.

\section{CONCLUSÃO E CONSIDERAÇÕES FINAIS}

Os estudos acerca da existência do Equilíbrio de Baixo Nível no Brasil permitem diversas conclusôes. Em geral, a qualidade dos serviços de abastecimento urbano de água e de esgotamento sanitário pode ser qualificada como sendo de baixo nível, especialmente se avaliados com base nos índices de cobertura e do superemprego no setor. Constituem exceçóes a essa regra os serviços dos Estados de São Paulo e Minas Gerais (no Sudeste) e do Distrito Federal (no Centro-Oeste). Os Estados do Sul possuem bons indicadores de abastecimento de água, mas o porcentual de domicílios com rede coletora de esgoto ainda é muito baixo, com exceção da Região Metropolitana de Curitiba, que apresenta bons indicadores tanto em termos dos serviços de água quanto de esgoto.

Em termos de atendimento de água, os serviços prestados diretamente pelo município são significativamente melhores do que aqueles prestados por Companhias Estaduais de Saneamento, independentemente da região ou estado. Por outro lado, as poucas 
concessões ao setor privado, que surgiram a partir de 1995, ainda não produziram melhorias significativas. Inclusive, em $47 \%$ dos casos, as tarifas não cobriram as despesas totais dos serviços dessas empresas no ano de 1999. Na verdade, na maior parte dos serviços analisados, a tarifa média cobrada não paga o custo dos serviços por metro cúbico, principalmente quando prestados por uma Companhia Estadual de Saneamento (CESB). Uma conseqüência dessa realidade é que o setor continua dependendo de recursos não onerosos (transferências governamentais) para financiar os investimentos.

A inexistência de um modelo institucional e regulatório em nível federal, que estabeleça diretrizes gerais e as condições de regulação e de fiscalização da prestação de serviços, mantém viva a possibilidade de um EBN: que é a dos governos estaduais e/ou municipais interferirem inadequadamente na política tarifária. Não obstante, a instabilidade política, do ponto de vista macroeconômico, não é a condicionante fundamental para a falta de investimentos no setor, uma vez que o processo de privatização e de concessão dos serviços de utilidade pública tem sido bem-sucedido em outros setores. Não podem ser esquecidas, no entanto, duas particularidades importantes que caracterizam o caso brasileiro: i) os reajustes tarifários muita vezes foram manipulados por políticas antiinflacionárias; ii) os reajustes tarifários estão associados à renda, que juntamente com a capacidade do setor público em financiar os serviços determinam índices diferenciados entre regióes ricas e as mais pobres.

Pelo menos dois pontos merecem um estudo mais específico. Devem ser investigadas as razões pelas quais não tem sido permitida a melhoria esperada dos serviços que foram concedidos ao setor privado. Certamente tal propósito requer uma análise individual dos contratos de concessão e das condições gerais em que tais serviços foram entregues ao setor privado. Outro ponto importante a ser analisado é medir os futuros impactos da cobrança da água (institucionalizada pela nova Política Nacional de Recursos Hídricos) no equilíbrio econômico-financeiro dos prestadores de serviços, bem como a capacidade e a viabilidade dessa cobrança ser repassada aos consumidores. Dentro dessa perspectiva, surge ainda outra questão: o que faz crer que esta cobrança será feita corretamente se as mesmas condicionantes do EBN continuam existindo?

\section{BIBLIOGRAFIA}

ARTANA, D. et alii. Governance and regulation: a tale of two concessions in Argentina. In: SAVEDOFF, W. D.; SPILLER, P. T., Spilled water: institutional commitment in the provision of water services. Washington, D. C.: Inter American Development Bank, 1999.

EMERCIANO, E.; BALTAR, L. A. Flexibilização institucional da prestação de serviços de saneamento: implicações e desafios. Acqua-Plan - Estudos, Projetos e Con- 
sultoria. Brasília: Ministério do Planejamento e Orçamento. Secretaria de Política Urbana. IPEA, 1995. (Série Modernização do Setor Saneamento,3).

HOLANDA, N. C. et alii. Regulação da prestação de serviços de saneamento: análise comparada da legislação internacional. NH Consultoria e Planejamento. Brasília: Ministério do Planejamento e Orçamento. Secretaria de Política Urbana/IPEA, 1995, 278 p. (Série Modernização do Setor Saneamento, 6).

LEVY, B.; SPILLER, P. T. The institutional foundations of regulatory commitment: a comparative analysis of five country studies of telecommunications regulation. Journal of Law, Economics, and Organization, v. 10, n. 2, p. 201-46, 1994.

MÉNARD, C.; SHIRLEY, M. Reforming Public utilities: lessons from urban systems in six developing countries. Anais do II Seminário Brasileiro da Nova Economia Institucional, Campinas: Unicamp, 2001.

MORANDÉ, F; DOÑA, J. E. Governance and regulation in Chile: fragmentation of the public water sector. In: SAVEDOFF, W. D.; SPILLER, P. T., Spilled water: institutional commitment in the provision of water services. Washington, D. C.: Inter American Development Bank, 1999.

MUELLER, B.; PEREIRA, C. Credibility and the design of regulatory agencies in Brazil. Brazilian Journal of Political Economy, v. 22, n. 3 (87), p. 65-88, julysept. 2001.

OZUMA, T. J.; GÓMEZ, I. A. Governance and regulation: decentralization in Mexico's water sector. In: SAVEDOFF, W. D.; SPILLER, P. T., Spilled water: institutional commitment in the provision of water services. Washington, D. C.: Inter American Development Bank, 1999.

PEREIRA, D. S. P.; BALTAR, L. A. A.; ABICALIL, M. T. Saneamento: modernização e parceria com o setor privado. Brasília: Ministério do Planejamento e Orçamento. Secretaria de Política Urbana/IPEA, 1995 (Série Modernização do Setor Saneamento, 9).

REZENDE, F. et alii. Novo modelo de financiamento para o setor saneamento. Brasília: Ministério do Planejamento e Orçamento. Secretaria de Política Urbana/ IPEA, 1995, 204 p. (Série Modernização do Setor saneamento, 2).

SHIRLEY, M.; XU, L. C. Information, incentives and commitment: an empirical analysis of contracts between government and state enterprises. Word Bank Paper 1976. Washington, DC., 1996.

SILVA, R. T. Fundamentos e proposta de ordenamento institucional. Núcleo de Pesquisas em Informações Urbanas da Universidade de São Paulo - INFURB. Brasília: Ministério do Planejamento e Orçamento. Secretaria de Política Urbana/IPEA, 1995a (Série de Modernização do Setor Saneamento,1).

SILVA, J. A. C. Diagnóstico do setor de saneamento: estudo econômico e financeiro. Aliança - Pesquisa e Desenvolvimento. Brasília: Ministério do Planejamento e Orçamento. Secretaria de Política Urbana/IPEA, 1995b. 25lp. (Série Modernização do Setor Saneamento, v. 4). 
SPILLER, P. T.; SAVEDOFF, W. D. Government opportunism and the provision of water. In: SAVEDOF, W. D.; SPILLER, P. T., Spilled water: institutional commitment in the provision of water services. Washington, D. C.: Inter American Development Bank, 1999.

TAMAYO, G. et alii. Reform efforts and low-level equilibrium in the Peruvian water sector. In: SAVEDOF, W. D.; SPILLER, P. T., Spilled water: institutional commitment in the provision of water services. Washington, D. C.: Inter American Development Bank, 1999.

WALKER, I. et alii. Reform efforts and low-level equilibrium in the Honduran water sector. In: SAVEDOFF, W. D.; SPILLER, P. T., Spilled water: institutional commitment in the provision of water services. Washington, D. C.: Inter American Development Bank, 1999. 
ANEXO - Tabelas

TABELA A - PORCENTUAL DE DOMICÍLIOS ATENDIDOS COM ÁGUA E ESGOTAMENTO SANITÁRIO, POR GRANDES REGIÓES, UNIDADES DA FEDERAÇÃO E REGIÓES METROPOLITANAS

\begin{tabular}{|c|c|c|c|c|c|c|}
\hline \multirow[t]{2}{*}{$\begin{array}{l}\text { Grandes Regiões, } \\
\text { Unidades da Federação e } \\
\text { Regiões Metropolitanas }\end{array}$} & $\begin{array}{r}A \\
\text { Percen } \\
\text { Can }\end{array}$ & $\begin{array}{l}\text { mento } \\
\text { domici } \\
\text { em red }\end{array}$ & $\begin{array}{l}\text { água } \\
(\%)\end{array}$ & $\begin{array}{l}\text { Perc } \\
\text { Red }\end{array}$ & $\begin{array}{l}\text { nento s } \\
\text { de dom } \\
\text { ora de }\end{array}$ & $\begin{array}{l}\text { com } \\
(\%)\end{array}$ \\
\hline & 1992 & 1999 & 92/99 & 1992 & 1999 & 92/99 \\
\hline Brasil & 83,3 & 89,2 & 7,1 & 48,0 & 52,5 & 9,4 \\
\hline Norte & 56,8 & 61,1 & 7,6 & 7,2 & 8,2 & 13,9 \\
\hline Rondônia & 52,7 & 55,1 & 4,6 & 0,6 & 4,4 & 633,3 \\
\hline Acre & 51,7 & 43,9 & $-15,1$ & 227,4 & 34,2 & 24,8 \\
\hline Amazonas & 77,8 & 79,4 & 2,1 & 18,3 & 20,5 & 12,0 \\
\hline Roraima & 76,6 & 93,6 & 22,2 & 0,9 & 0,6 & $-33,3$ \\
\hline Pará & 45,5 & 47,7 & 4,8 & 2,5 & 2,4 & $-4,0$ \\
\hline Região Metropolitana de Belém & 74,3 & 76,8 & 3,4 & 6,5 & 7,7 & 18,5 \\
\hline Amapá & 79,5 & 55,1 & $-30,7$ & 1,4 & 0,4 & $-71,4$ \\
\hline Tocantins & 43,5 & 75,6 & 73,8 & - & 0,8 & \\
\hline Nordeste & 70,6 & 80,9 & 14,6 & 19,3 & 28,1 & 45,6 \\
\hline Maranhão & 41,8 & 58,9 & 40,9 & 4,9 & 9,2 & 87,8 \\
\hline Piauí & 62,8 & 75,4 & 20,1 & 0,0 & 3,5 & \\
\hline Ceará & 63,1 & 76,9 & 21,9 & 8,5 & 24,0 & 182,4 \\
\hline Região Metropolitana de Fortaleza & 66,9 & 79,9 & 19,4 & 12,8 & 34,7 & 171,1 \\
\hline Rio Grande do Norte & 68,6 & 88,5 & 29,0 & 15,5 & 27,0 & 74,2 \\
\hline Paraíba & 85,9 & 92,0 & 7,1 & 29,3 & 35,5 & 21,2 \\
\hline Pernambuco & 78,8 & 83,1 & 5,5 & 27,0 & 34,9 & 29,3 \\
\hline Região Metropolitana de Recife & 82,9 & 82,9 & 0,0 & 27,7 & 35,2 & 27,1 \\
\hline Alagoas & 76,0 & 80,2 & 5,5 & 10,5 & 11,0 & 4,8 \\
\hline Sergipe & 80,5 & 94,4 & 17,3 & 27,9 & 21,9 & $-21,5$ \\
\hline Bahia & 71,0 & 81,9 & 15,4 & 25,2 & 37,9 & 50,4 \\
\hline Região Metropolitana de Salvador & 84,8 & 94,5 & 11,4 & 36,0 & 59,2 & 64,4 \\
\hline Sudeste & 91,0 & 94,9 & 4,3 & 73,8 & 78,8 & 6,8 \\
\hline Minas Gerais & 87,0 & 94,3 & 8,4 & 73,1 & 84,2 & 15,2 \\
\hline Região Metropolitana de Belo Horizonte & 91,7 & 97,3 & 6,1 & 74,3 & 86,9 & 17,0 \\
\hline Espírito Santo & 86,2 & 95,5 & 10,8 & 57,2 & 60,8 & 6,3 \\
\hline Rio de Janeiro & 85,4 & 88,7 & 3,9 & 57,5 & 58,6 & 1,9 \\
\hline Região Metropolitana do Rio de Janeiro & 87,6 & 90,3 & 3,1 & 56,2 & 59,3 & 5,5 \\
\hline São Paulo & 95,3 & 97,8 & 2,6 & 82,2 & 86,6 & 5,4 \\
\hline Região Metropolitana de São Paulo & 96,2 & 97,5 & 1,4 & 77,8 & 82,6 & 6,2 \\
\hline Sul & 87,6 & 93,9 & 7,2 & 19,5 & 22,0 & 12,8 \\
\hline Paraná & 89,6 & 96,4 & 7,6 & 26,9 & 38,8 & 44,2 \\
\hline Região Metropolitana de Curitiba & 88,9 & 97,1 & 9,2 & 38,8 & 56,6 & 45,9 \\
\hline Santa Catarina & 83,9 & 90,7 & 8,1 & 9,9 & 11,1 & 12,1 \\
\hline Rio Grande do Sul & 87,5 & 93,1 & 6,4 & 17,3 & 12,1 & $-30,1$ \\
\hline Região Metropolitana de Porto Alegre & 90,3 & 93,2 & 3,2 & 22,8 & 4,9 & $-78,5$ \\
\hline Centro-Oeste & 72,5 & 82,7 & 14,1 & 36,1 & 39,4 & 9,1 \\
\hline Mato Grosso do Sul & 76,6 & 88,8 & 15,9 & 6,8 & 7,7 & 13,2 \\
\hline Mato Grosso & 68,8 & 72,9 & 6,0 & 16,8 & 16,9 & 0,6 \\
\hline Goiás & 65,0 & 80,1 & 23,2 & 37,5 & 40,1 & 6,9 \\
\hline Distrito Federal & 88,6 & 92,4 & 4,3 & 79,7 & 89,7 & 12,5 \\
\hline
\end{tabular}

Fonte: Pesquisa nacional por amostra de domicílios 1992: microdados. Rio de Janeiro: IBGE, 1997; Pesquisa nacional por amostra de domicílios 1999: microdados: IBGE, 2000. 
TABELA B - QUANTIDADE DE EMPREGOS POR 1.000 LIGAÇÕES E ESTATÍS-

\begin{tabular}{|c|c|c|c|c|c|c|c|}
\hline \multirow{3}{*}{$\begin{array}{l}\text { Prestadores } \\
\text { de serviços } \\
\text { Siglas/Municípios }\end{array}$} & \multirow[b]{3}{*}{ Quant. } & \multicolumn{6}{|c|}{ Quantidade de empregados/1000 ligações } \\
\hline & & \multirow{2}{*}{$\begin{array}{l}\text { Indicador } \\
\text { Individual }\end{array}$} & \multicolumn{5}{|c|}{ Estatísticas } \\
\hline & & & Mediana & Max. & Min. & $\begin{array}{l}\text { Desvio } \\
\text { padrão }\end{array}$ & Assimetria \\
\hline$\overline{\text { CESBS }^{1}}$ & 26 & 4,0 & 4,3 & 27,4 & 2,0 & 4,9 & 3,8 \\
\hline CAER - PR & & 6,5 & & & & & \\
\hline CAERD - RO & & 9,3 & & & & & \\
\hline COSAMA - AM & & 4,9 & & & & & \\
\hline COSANPA - PA & & 4,6 & & & & & \\
\hline DEAS - AC & & 27,4 & & & & & \\
\hline SANEATINS - TO & & 4,8 & & & & & \\
\hline AGESIPA - PI & & 4,6 & & & & & \\
\hline CAEMA - MA & & 5,4 & & & & & \\
\hline CAERN - RN & & 4,3 & & & & & \\
\hline CAGECE - CE & & 2,0 & & & & & \\
\hline CAGEPA - PB & & 3,6 & & & & & \\
\hline CASAL - AL & & 4,8 & & & & & \\
\hline COMPESA - PE & & 3,9 & & & & & \\
\hline DESO - SE & & 3,6 & & & & & \\
\hline EMBASA -BA & & 3,0 & & & & & \\
\hline CEDAE - RJ & & 6,0 & & & & & \\
\hline CESAN - ES & & 2,9 & & & & & \\
\hline COPASA - MG & & 4,2 & & & & & \\
\hline SABESP - SP & & 3,9 & & & & & \\
\hline CASAN-RS & & 3,0 & & & & & \\
\hline CORSAN - SC & & 3,3 & & & & & \\
\hline SANEPAR - PR & & 3,1 & & & & & \\
\hline CAESB - DF & & 8,7 & & & & & \\
\hline SANEAGO - GO & & 4,0 & & & & & \\
\hline SANEMAT - MT & & 11,6 & & & & & \\
\hline SANESUL - MS & & 3,7 & & & & & \\
\hline Micro e Locais Privadas ${ }^{2}$ & 15 & - & 5,8 & 10,5 & 2,7 & 2,1 & 0,3 \\
\hline Birigüi - SP & & 4,5 & & & & & \\
\hline Cachoeiro de Itapemirim - ES & & 5,8 & & & & & \\
\hline $\mathrm{CAJ}-\mathrm{RJ}$ & & 4,6 & & & & & \\
\hline Itu - SP & & 10,5 & & & & & \\
\hline Jundiaí - SP & & 6,9 & & & & & \\
\hline Limeira - SP & & 2,8 & & & & & \\
\hline Mairinque - SP & & 8,2 & & & & & \\
\hline Marília-SP & & 7,4 & & & & & \\
\hline Nova Friburgo - RJ & & 7,2 & & & & & \\
\hline Ourinhos - SP & & 5,5 & & & & & \\
\hline Paranaguá - PR & & 3,9 & & & & & \\
\hline Petrópolis - RJ & & 5,4 & & & & & \\
\hline Ribeirão Preto - SP & & 6,9 & & & & & \\
\hline Salto - SP & & 2,7 & & & & & \\
\hline São Carlos - SP & & 6,7 & & & & & \\
\hline Micro e Locais - Públicos & 145 & - & 5,3 & 21,7 & 1,6 & 2,7 & 1,9 \\
\hline
\end{tabular}

Fonte: Diagnóstico dos Serviços de Água e Esgoto - 1999/SNIS.

(1) Este indicador não foi obtido para o caso da CAESA/AP. (2) Serviços que estão sob concessão de empresas privadas. Fonte: ABCON - Associação Brasileira das Concessionárias de Serviços de Água e Esgoto. Situação atualizada em setembro/2001. Estão relacionados aqueles serviços que tiveram data inicial de operação em 1999 ou antes e participaram do SNIS 1999. 
TABELA C - EVOLUÇÃO DA MARGEM DE LUCRO DAS COMPANHIAS ESTADUAIS: 1995-1999 ${ }^{1}$

\begin{tabular}{|c|c|c|c|c|c|}
\hline \multirow{2}{*}{$\begin{array}{l}\text { Companhias } \\
\text { Estaduais (CESBs) }\end{array}$} & \multicolumn{5}{|c|}{ Margem de lucro - $\mathrm{R} \$ / \mathrm{m}^{3}$} \\
\hline & 1995 & 1996 & 1997 & 1998 & 1999 \\
\hline$\overline{C A E R}-\mathrm{PR}$ & $-0,81$ & $-1,58$ & $-1,30$ & $-0,69$ &,- 64 \\
\hline CAERD - RO & $-0,40$ &,- 132 & $-0,34$ & $-1,49$ & 0,04 \\
\hline $\mathrm{CAESA}_{-}-\mathrm{AP}$ & $-0,07$ & $-0,11$ & $-0,11$ & $-0,74$ & $-0,56$ \\
\hline COSAMA - AM & $-0,50$ & $-0,25$ & $-0,31$ & $-0,36$ & $-0,61$ \\
\hline COSANPA - PA & $-0,14$ & $-0,39$ & $-0,46$ & $-0,30$ & $-0,29$ \\
\hline DEAS - AC & $-0,71$ & & & $-2,53$ & $-1,44$ \\
\hline SANEATINS - TO & 0,29 & $-0,09$ & & 0,15 & 0,12 \\
\hline Norte & & $-0,39$ & $-0,45$ & $-0,44$ & $-0,36$ \\
\hline AGESIPA - PI & $-0,21$ & 0,02 & $-0,06$ & -029 & $-0,21$ \\
\hline CAEMA - MA & $-0,10$ & $-0,40$ & 0,00 & $-0,31$ & $-0,99$ \\
\hline CAERN - RN & $-0,14$ & $-0,05$ & 0,00 & $-0,06$ & $-0,28$ \\
\hline CAGECE - CE & $-0,08$ & $-0,05$ & 0,01 & $-0,07$ & 0,03 \\
\hline CAGEPA - PB & 0,02 & 0,05 & $-0,17$ & $-0,11$ & $-0,15$ \\
\hline CASAL - AL & $-0,36$ & $-0,32$ & $-0,42$ & $-0,26$ & $-0,24$ \\
\hline COMPESA - PE & $-0,07$ & $-0,01$ & 0,09 & $-0,12$ & $-0,18$ \\
\hline DESO - SE & $-0,08$ & $-0,06$ & $-0,06$ & $-0,18$ & $-0,04$ \\
\hline EMBASA -BA & 0,00 & 0,00 & $-0,10$ & $-0,26$ & $-0,28$ \\
\hline Nordeste & & $-0,05$ & $-0,06$ & $-0,17$ & $-0,23$ \\
\hline CEDAE - RJ & 0,02 & $-0,05$ & 0,14 & 0,02 & $-0,19$ \\
\hline CESAN - ES & 0,06 & $-0,02$ & 0,02 & $-0,03$ & 0,01 \\
\hline COPASA - MG & $-0,12$ & $-0,11$ & 0,01 & $-0,02$ & $-0,03$ \\
\hline SABESP - SP & 0,00 & 0,14 & 0,17 & 0,18 & 0,30 \\
\hline Sudeste & & 0,04 & 0,13 & 0,10 & 0,15 \\
\hline CASAN-RS & $-0,01$ & 0,03 & 0,05 & $-0,02$ & 0,02 \\
\hline CORSAN - SC & $-0,35$ & $-0,24$ & $-0,13$ & $-0,25$ & 0,01 \\
\hline SANEPAR - PR & 0,05 & 0,01 & 0,07 & 0,03 & 0,12 \\
\hline Sul & & $-0,06$ & 0,01 & $-0,06$ & 0,07 \\
\hline CAESB - DF & $-0,24$ & $-0,04$ & $-0,12$ & $-0,05$ & $-0,04$ \\
\hline SANEAGO - GO & $-0,06$ & $-0,03$ & 0,05 & 0,06 & $-0,05$ \\
\hline SANEMAT - MT & $-0,05$ & $-0,25$ & 0,24 & $-0,09$ & $-2,16$ \\
\hline SANESUL - MS & $-0,31$ & $-0,10$ & $-0,11$ & $-0,19$ & $-0,24$ \\
\hline Centro- Oeste & & $-0,08$ & $-0,01$ & $-0,03$ & $-0,15$ \\
\hline Total Brasil & & 0,00 & 0,06 & 0,01 & 0,05 \\
\hline
\end{tabular}

Fonte: Diagnóstico dos Serviços de Água e Esgoto - 1995 a 1999/SNIS.

(1) A margem de lucro é definida como sendo a diferença entre a tarifa média praticada e o custo do serviço por metro cúbico. 
TABELA D - ÍNDICES DE TARIFAS E DE DESPESAS - $1995=1000$

\begin{tabular}{|c|c|c|c|c|c|c|c|c|c|c|c|}
\hline \multirow{2}{*}{$\begin{array}{l}\text { Companhia/UF } \\
\text { Sigla }\end{array}$} & \multicolumn{5}{|c|}{ Índices de Tarifas } & \multicolumn{5}{|c|}{ Índices de Despesas } & \multirow{2}{*}{$\begin{array}{c}\text { Diferença } \\
\text { Acumulada }\end{array}$} \\
\hline & 1995 & 1996 & 1997 & 1998 & 1999 & 1995 & 1996 & 1997 & 1998 & 1999 & \\
\hline CAER - PR & 100 & 120 & 147 & 153 & 159 & 100 & 165 & 155 & 113 & 111 & 48 \\
\hline CAERD - RO & 100 & 318 & 125 & 162 & 184 & 100 & 322 & 112 & 230 & 122 & 62 \\
\hline CAESA - AP & 100 & 83 & 155 & 145 & 172 & 100 & 93 & 156 & 263 & 253 & -81 \\
\hline COSAMA - AM & 100 & 129 & 177 & 160 & 171 & 100 & 95 & 127 & 122 & 150 & 21 \\
\hline COSANPA - PA & 100 & 108 & 118 & 165 & 168 & 100 & 141 & 158 & 174 & 175 & -7 \\
\hline DEAS - AC & 100 & & & 132 & 131 & 100 & & & 228 & 161 & -31 \\
\hline SANEATINS - TO & 100 & 126 & & 131 & 122 & 100 & 237 & & 188 & 181 & -58 \\
\hline AGESIPA - PI & 100 & 120 & 144 & 169 & 185 & 100 & 90 & 117 & 162 & 165 & 20 \\
\hline CAEMA - MA & 100 & 123 & 167 & 165 & 153 & 100 & 171 & 138 & 190 & 298 & -145 \\
\hline CAERN - RN & 100 & 151 & 178 & 182 & 178 & 100 & 124 & 136 & 149 & 184 & -6 \\
\hline CAGECE - CE & 100 & 123 & 137 & 130 & 147 & 100 & 114 & 114 & 124 & 117 & 30 \\
\hline CAGEPA - PB & 100 & 136 & 155 & 157 & 157 & 100 & 131 & 200 & 189 & 198 & -40 \\
\hline CASAL - AL & 100 & 117 & 153 & 171 & 186 & 100 & 106 & 139 & 133 & 140 & 46 \\
\hline COMPESA - PE & 100 & 125 & 154 & 160 & 149 & 100 & 112 & 120 & 161 & 162 & -13 \\
\hline DESO - SE & 100 & 124 & 147 & 154 & 168 & 100 & 118 & 139 & 163 & 155 & 13 \\
\hline EMBASA -BA & 100 & 111 & 121 & 137 & 118 & 100 & 111 & 137 & 178 & 163 & -44 \\
\hline CEDAE - RJ & 100 & 134 & 148 & 166 & 162 & 100 & 148 & 129 & 168 & 202 & -40 \\
\hline CESAN - ES & 100 & 119 & 142 & 142 & 150 & 100 & 138 & 155 & 166 & 166 & -17 \\
\hline COPASA - MG & 100 & 136 & 151 & 162 & 165 & 100 & 126 & 118 & 132 & 135 & 30 \\
\hline SABESP - SP & 100 & 104 & 119 & 115 & 132 & 100 & 87 & 99 & 94 & 96 & 35 \\
\hline CASAN-RS & 100 & 131 & 155 & 161 & 164 & 100 & 125 & 147 & 161 & 159 & 5 \\
\hline CORSAN - SC & 100 & 164 & 196 & 181 & 216 & 100 & 135 & 147 & 147 & 148 & 68 \\
\hline SANEPAR - PR & 100 & 116 & 133 & 143 & 150 & 100 & 124 & 132 & 150 & 143 & 7 \\
\hline CAESB - DF & 100 & 147 & 160 & 154 & 159 & 100 & 109 & 127 & 115 & 116 & 43 \\
\hline SANEAGO - GO & 100 & 120 & 136 & 146 & 149 & 100 & 114 & 115 & 123 & 143 & 7 \\
\hline SANEMAT - MT & 100 & 126 & 124 & 122 & 116 & 100 & 149 & 86 & 125 & 382 & -282 \\
\hline SANESUL - MS & 100 & 125 & 129 & 134 & 142 & 100 & 98 & 102 & 113 & 145 & -3 \\
\hline Índice médio ${ }^{1}$ & 100 & 135 & 146 & 151 & 157 & 100 & 136 & 130 & 157 & 163 & -6 \\
\hline
\end{tabular}

Fonte: Diagnóstico dos Serviços de Água e Esgoto - 1995 a 1999/SNIS.

$$
I_{t}=\frac{\sum_{i=1}^{n} p_{t}^{i}}{\sum_{i=1}^{n} p_{0}^{i}}
$$

onde $p_{t}^{i}$ é a tarifa (ou custo) no ano $t$ da companhia $i, p_{o}^{i}$ é a tarifa (ou custo) no ano base (1995) da companhia $i$ e $I_{t}$ é o índice médio de tarifas (ou custos) das companhias no ano $t$. 


\section{TABELA E - ESTATÍSTICAS DAS MARGENS DE DESPESAS COM PESSOAL TOTAL OCUPADO NOS SERVIÇOS}

\begin{tabular}{|c|c|c|c|c|c|c|c|}
\hline \multirow{3}{*}{$\begin{array}{l}\text { Prestadores } \\
\text { de serviços } \\
\text { Siglas/Municíios }\end{array}$} & \multirow[b]{3}{*}{ Quant. } & \multicolumn{6}{|c|}{ Quantidade de empregados $/ 1000$ ligaçôes } \\
\hline & & \multirow{2}{*}{$\begin{array}{c}\text { Indicador } \\
\text { Individual } \\
\%\end{array}$} & \multicolumn{4}{|c|}{ Estatísticas } & \multirow[b]{2}{*}{$\begin{array}{c}\text { Assimetria } \\
\%\end{array}$} \\
\hline & & & $\begin{array}{c}\text { Mediana } \\
\%\end{array}$ & $\begin{array}{c}\text { Max. } \\
\%\end{array}$ & $\begin{array}{c}\text { Min. } \\
\%\end{array}$ & $\begin{array}{l}\text { Desvio } \\
\text { padrão }\end{array}$ & \\
\hline$\overline{\text { CESBS }^{1}}$ & 27 & & 56,6 & 198,8 & 19,5 & 35,3 & 2,6 \\
\hline CAER - PR & & 50,1 & & & & & \\
\hline CAERD - RO & & 55,5 & & & & & \\
\hline CAESA - AP & & 72,4 & & & & & \\
\hline COSAMA - AM & & 58,2 & & & & & \\
\hline COSANPA - PA & & 52,1 & & & & & \\
\hline DEAS - AC & & 198,8 & & & & & \\
\hline SANEATINS - TO & & 19,5 & & & & & \\
\hline AGESIPA - PI & & 65,3 & & & & & \\
\hline CAEMA - MA & & 67,3 & & & & & \\
\hline CAERN - RN & & 64,6 & & & & & \\
\hline CAGECE - CE & & 56,6 & & & & & \\
\hline CAGEPA - PB & & 79,6 & & & & & \\
\hline CASAL - AL & & 75,3 & & & & & \\
\hline COMPESA - PE & & 87,8 & & & & & \\
\hline DESO - SE & & 63,6 & & & & & \\
\hline EMBASA -BA & & 50,2 & & & & & \\
\hline CEDAE - RJ & & 32,2 & & & & & \\
\hline CESAN - ES & & 49,6 & & & & & \\
\hline COPASA-MG & & 48,1 & & & & & \\
\hline SABESP - SP & & 28,5 & & & & & \\
\hline CASAN-RS & & 59,8 & & & & & \\
\hline CORSAN - SC & & 47,3 & & & & & \\
\hline SANEPAR - PR & & 42,5 & & & & & \\
\hline CAESB - DF & & 60,1 & & & & & \\
\hline SANEAGO - GO & & 51,2 & & & & & \\
\hline SANEMAT - MT & & 146,6 & & & & & \\
\hline SANESUL - MS & & 55,1 & & & & & \\
\hline Micro e Locais Privadas ${ }^{2}$ & 17 & $\cdot$ & 49,1 & 82,8 & 13,4 & 19,0 & 0,2 \\
\hline Araçatuba & & 75,9 & & & & & \\
\hline Birigüi - SP & & 27,8 & & & & & \\
\hline Cachoeiro de Itapemirim - ES & & 34,7 & & & & & \\
\hline CAJ-RJ & & 33,9 & & & & & \\
\hline Itu - SP & & 82,8 & & & & & \\
\hline Jundiaí - SP & & 50,6 & & & & & \\
\hline Limeira - SP & & 35,5 & & & & & \\
\hline Mairinque - SP & & 49,1 & & & & & \\
\hline Marília-SP & & 63,5 & & & & & \\
\hline Nova Friburgo - RJ & & 66,3 & & & & & \\
\hline Ourinhos - SP & & 46,1 & & & & & \\
\hline Paranaguá - PR & & 49,6 & & & & & \\
\hline Petrópolis - RJ & & 30,1 & & & & & \\
\hline PROLAGOS - RJ & & 28,5 & & & & & \\
\hline Ribeirão Preto - SP & & 59,4 & & & & & \\
\hline Salto - SP & & 13,4 & & & & & \\
\hline São Carlos - SP & & 62,7 & & & & & \\
\hline Micro e Locais - Públicos & 148 & - & 58,4 & 396,4 & 11,1 & 34,1 & 6,5 \\
\hline Total - Brasil & 192 & - & 57,3 & 396,4 & 396,4 & 33,3 & 5,8 \\
\hline
\end{tabular}

Fonte: Estatísticas calculadas com base nos dados do Diagnóstico dos Serviços de Água e Esgoto - 1999/ SNIS.

(1) Serviços que estão sob concessão de empresas privadas. Fonte: ABCON - Associação Brasileira das Concessionárias de Serviços de Água e Esgoto. Situação atualizada em setembro/2001. Estão relacionados aqueles serviços que tiveram data inicial de operação em 1999 ou antes e participaram do SNIS 1999. 
TABELA F - INVESTIMENTOS EM SANEAMENTO BÁSICO COM RECURSOS DO PLANASA/PRONURB E DO OGU E A PARTICIPAÇÃO DO FGTS - 1980/93

\begin{tabular}{|c|c|c|c|c|c|}
\hline \multirow[t]{2}{*}{ Ano } & \multicolumn{2}{|c|}{ Planasa/Pronurb $^{1}$} & \multirow{2}{*}{$\begin{array}{c}\text { OGU² } \\
\text { U\$ milhões }\end{array}$} & \multirow{2}{*}{$\begin{array}{c}\text { Total } \\
\text { U\$ milhões }\end{array}$} & \multirow{2}{*}{$\begin{array}{l}\text { \% do } \\
\mathrm{OGU}^{4}\end{array}$} \\
\hline & U\$ milhões & $\%$ do FGTS 3 & & & \\
\hline 1968 & 1,4 & 32,1 & - & - & - \\
\hline 1969 & 69,1 & 11,6 & - & - & - \\
\hline 1970 & 140,7 & 13,3 & - & - & - \\
\hline 1971 & 55,4 & 26,5 & - & - & - \\
\hline 1972 & 130,8 & 21,7 & - & - & - \\
\hline 1973 & 303,6 & 21,6 & - & - & - \\
\hline 1974 & 342,4 & 22,5 & - & - & - \\
\hline 1975 & 509,8 & 20,6 & - & - & - \\
\hline 1976 & 577,4 & 22,3 & - & - & - \\
\hline 1977 & 704,9 & 23,7 & - & - & - \\
\hline 1978 & 840,4 & 24,5 & - & - & - \\
\hline 1979 & 848,2 & 26,7 & - & - & - \\
\hline 1980 & $1.125,1$ & 28,4 & 30,0 & $1.155,1$ & 2,6 \\
\hline 1981 & $1.409,7$ & 38,7 & 54,0 & $1.463,7$ & 3,7 \\
\hline 1982 & $1.258,7$ & 40,2 & 42,1 & $1.300,8$ & 3,2 \\
\hline 1983 & 671,0 & 63,9 & 20,3 & 691,3 & 2,9 \\
\hline 1984 & 428,6 & 63,3 & 16,5 & 445,1 & 3,7 \\
\hline 1985 & 709,7 & 68,4 & 23,1 & 732,7 & 3,2 \\
\hline 1986 & 743,9 & 47,6 & 31,6 & 775,5 & 4,1 \\
\hline 1987 & 963,2 & 56,0 & 51,1 & $1.014,3$ & 5,0 \\
\hline 1988 & $1.288,7$ & 71,1 & 46,8 & $1.335,5$ & 3,5 \\
\hline 1989 & 817,9 & 66,0 & 102,3 & 920,2 & 11,1 \\
\hline 1990 & 885,1 & 66,5 & 138,9 & $1.024,0$ & 13,6 \\
\hline 1991 & 804,4 & 89,6 & 275,0 & $1.079,4$ & 25,5 \\
\hline 1992 & 326,8 & 93,1 & 429,0 & 755,8 & 56,8 \\
\hline 1993 & 234,6 & 99,7 & 442,4 & 677,0 & 65,3 \\
\hline
\end{tabular}

Fonte: Elaborado em SILVA (1995B) e REZENDE et alli (1995), a partir de dados do Balanço Geral da União e da CEF/BNH.

(1) Planasa em 1968/89 e Pronurb a partir de 1990. Investimentos realizados em água, esgoto, drenagem urbana e na rubrica "outros". (2) Investimentos realizados pelo Tesouro Nacional nos subprogramas Abastecimento de Água, Saneamento Geral e Sistemas de Esgoto. (3) Porcentual dos recursos do FGTS em relação aos empréstimos totais do Planasa e Pronurb. (4) Porcentual dos recursos do OGU em relação ao total de investimentos (Planasa/Pronurb + OGU). 


\begin{tabular}{|c|c|c|c|c|c|}
\hline \multirow{2}{*}{$\begin{array}{l}\text { Prestadores de serviços, } \\
\text { Segundo grupos }\end{array}$} & \multirow[b]{3}{*}{ Quant. } & \multirow{2}{*}{$\begin{array}{l}\text { Investimento } \\
\text { Total }\end{array}$} & \multicolumn{3}{|c|}{ Origem dos recursos } \\
\hline & & & Próprios & Onerosos & Não onerosos \\
\hline Nome ou município & & $\mathrm{R} \$$ /ano & $\%$ & $\%$ & $\%$ \\
\hline CAER - PR & & 2.453 .687 & 100,0 & 0,0 & 0,0 \\
\hline CAERD - RO & & 3.683 .209 & 100,0 & 0,0 & 0,0 \\
\hline CAESA - AP & & 4.445 .543 & 0,0 & 0,0 & 100,0 \\
\hline COSAMA - AM & & 7.807 .904 & 17,1 & 0,0 & 82,9 \\
\hline COSANPA - PA & & 10.242 .549 & 23,2 & 0,0 & 61,4 \\
\hline DEAS - AC & & 0 & - & - & - \\
\hline SANEATINS - TO & & 22.798 .392 & 12,1 & 81,2 & 0,0 \\
\hline AGESIPA - PI & & 21.412 .930 & - & - & - \\
\hline CAEMA - MA & & 7.212 .774 & 18,1 & 0,0 & 46,4 \\
\hline CAERN - RN & & 18.133 .574 & 27,9 & 0,0 & 47,4 \\
\hline CAGECE - CE & & 58.327 .310 & 22,1 & 42,2 & 25,0 \\
\hline CAGEPA - PB & & 40.976 .314 & 20,5 & 32,2 & 47,3 \\
\hline CASAL - AL & & 4.184 .945 & 70,2 & 0,0 & 29,8 \\
\hline COMPESA - PE & & 42.789 .474 & 24,9 & 20,5 & 43,3 \\
\hline DESO - SE & & 37.910 .524 & 14,5 & 0,0 & 82,9 \\
\hline EMBASA -BA & & 227.018 .535 & 8,3 & 83,1 & 5,6 \\
\hline CEDAE - RJ & & 156.985.208 & 10,6 & 57,5 & 15,0 \\
\hline CESAN - ES & & 15.728 .535 & 36,4 & 63,6 & 0,0 \\
\hline COPASA - MG & & 146.005 .000 & 56,4 & 35,3 & 3,2 \\
\hline SABESP - SP & & 725.447 .862 & 74,8 & 9,8 & 0,0 \\
\hline CASAN-RS & & 60.288 .477 & 31,1 & 57,6 & 3,6 \\
\hline CORSAN - SC & & 90.177 .359 & 43,3 & 37,7 & 0,0 \\
\hline SANEPAR - PR & & 222.249 .067 & 30,6 & 40,0 & 19,3 \\
\hline CAESB - DF & & 42.703.208 & 56,2 & 9,5 & 11,4 \\
\hline SANEAGO - GO & & 68.781 .643 & 45,2 & 50,5 & 1,4 \\
\hline SANEMAT - MT & & 13.430 .975 & 22,3 & 0,0 & 55,6 \\
\hline SANESUL - MS & & 8.852 .000 & 2,8 & 62,3 & 17,3 \\
\hline Total das CESBs & 27 & 2.060 .046 .997 & 44,2 & 32,9 & 10,4 \\
\hline PROLAGOS -RJ & & 29.924 .011 & 0,0 & 100,0 & 0,0 \\
\hline Cahoeiro de Itapemirim - ES & & 4.251 .649 & 32,4 & 67,6 & 0,0 \\
\hline Limeira - SP & & 1.570 .419 & 100,0 & 0,0 & 0,0 \\
\hline Mairinque - SP & & 2.444 .810 & 36,0 & 64,0 & 0,0 \\
\hline Nova Friburgo - RJ & & 12.204 .646 & 100,0 & 0,0 & 0,0 \\
\hline Petrópolis - RJ & & 42.672 .036 & 21,8 & 78,2 & 0,0 \\
\hline Paranaguá - PR & & 5.163 .632 & 6,1 & 93,9 & 0,0 \\
\hline Biriguui - SP & & 442.239 & 30,0 & 0,0 & 70,0 \\
\hline Itu - SP & & 792.997 & 70,9 & 0,0 & 29,1 \\
\hline Jundiaí - SP & & 6.624 .408 & 99,2 & 0,8 & 0,0 \\
\hline Marília - SP & & 857.579 & 46,9 & 0,0 & 53,1 \\
\hline Ourinhos - SP & & 309.844 & 100,0 & 0,0 & 0,0 \\
\hline Salto -SP & & 1.180 .000 & 70,3 & 29,7 & 0,0 \\
\hline São Carlos - SP & & 3.890 .115 & 54,5 & 35,3 & 0,0 \\
\hline Total das concessões privadas ${ }^{1}$ & 15 & 112.328 .384 & 32,6 & 66,2 & 0,9 \\
\hline Total dos municipais públicos & 151 & 235.935.278 & 82,1 & 17,9 & 2,3 \\
\hline Total do Brasil & 193 & 2.408 .310 .660 & 47,3 & 33,0 & 9,2 \\
\hline
\end{tabular}

Fonte: Diagnóstico dos Serviços de Água e Esgoto - 1999/SNIS.

(1) Serviços que estão sob concessão de empresas privadas. Fonte: ABCON - Associação Brasileira das Concessionárias de Serviços de Água e Esgoto. Situação atualizada em setembro/2001. Estão relacionados aqueles municípios que tiveram data inicial de operação em 1999 ou antes e participaram do SNIS 1999. 


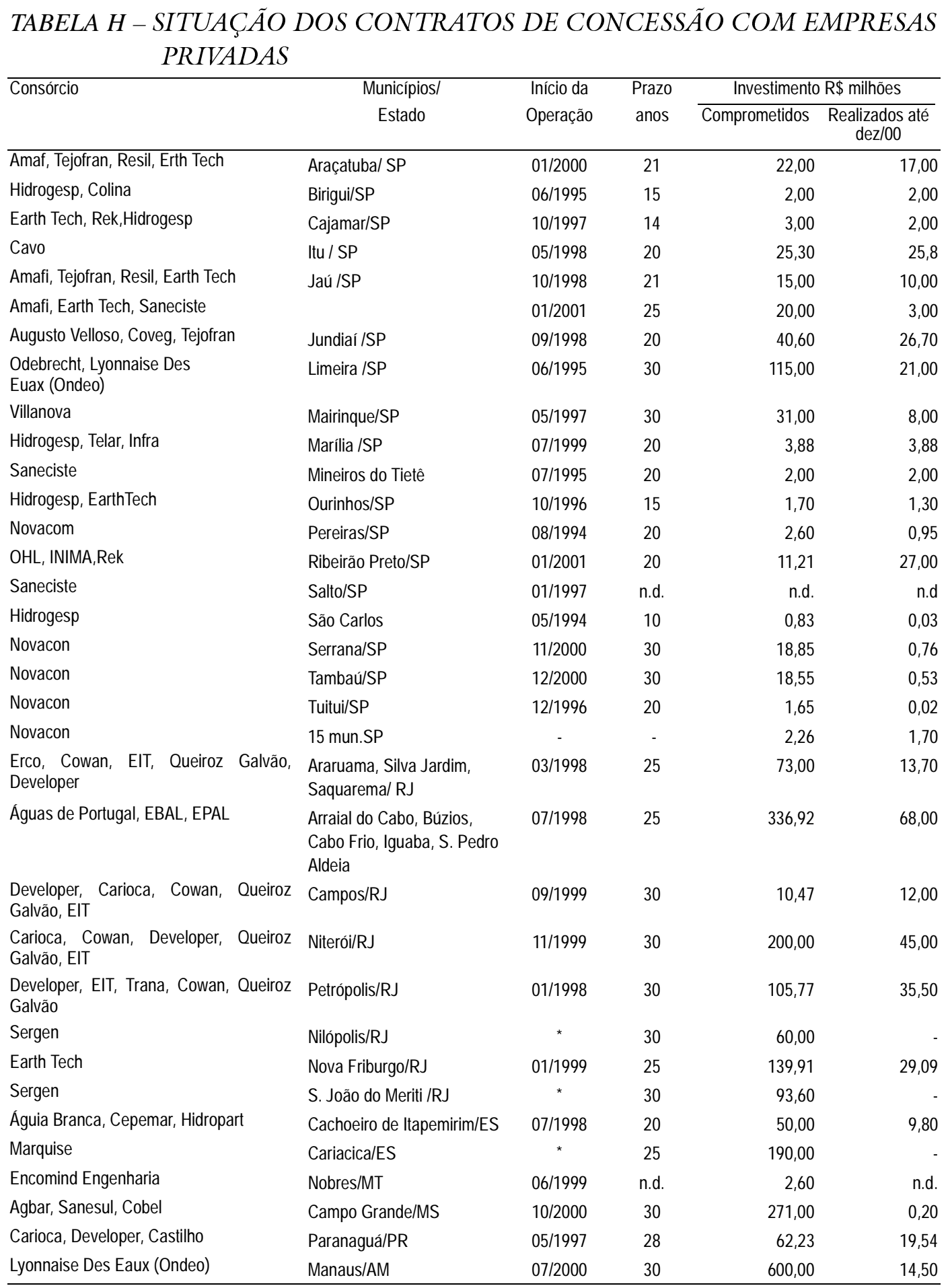

Fonte: ABCON - Associação Brasileira das Concessionárias de Serviços Públicos de Águas e Esgoto. Situação em setembro/2001.

(1) Serviços com a Concessão paralisada. (2) Permissóes. 
TABELA I - PARTICIPAÇÃO DO INVESTIDOR ESTRANGEIRO NO PND PLANO NACIONAL DE DESESTATIZAÇÃO - 1991/2001

\begin{tabular}{|c|c|c|c|c|c|c|c|}
\hline \multirow[t]{2}{*}{ Nacionalidade } & \multicolumn{2}{|c|}{$\begin{array}{c}\text { Setor de } \\
\text { Telecomunicações }\end{array}$} & \multicolumn{2}{|c|}{$\begin{array}{l}\text { Demais setores } \\
\text { Incluídos no PND }\end{array}$} & \multicolumn{2}{|c|}{$\begin{array}{c}\text { Privatizações e } \\
\text { Concessões Estaduais }\end{array}$} & \multirow{2}{*}{$\begin{array}{c}\text { Total } \\
\%\end{array}$} \\
\hline & U\$ milhões & $\%$ & U\$ milhões & $\%$ & U\$ milhões & $\%$ & \\
\hline USA & 3.692 & 12,8 & 4.318 & 15,3 & 6.024 & 21,6 & 14.034 \\
\hline Espanha & 5.027 & 17,5 & 3.606 & 12,8 & 4.027 & 14,4 & 12.675 \\
\hline Portugal & 4.224 & 14,7 & 1 & 0,0 & 658 & 2,4 & 4.883 \\
\hline Itália & 2.479 & 8,6 & - & - & 143 & 0,6 & 2.622 \\
\hline Chile & - & - & - & - & 1.006 & 3,6 & 1.006 \\
\hline Bélgica & - & - & 880 & 3,1 & - & - & 880 \\
\hline Inglaterra & 21 & 0,1 & 2 & 0,0 & 692 & 2,5 & 715 \\
\hline Canadá & 671 & 2,3 & 21 & 0,1 & - & - & 692 \\
\hline Suécia & 599 & 2,1 & - & - & - & - & 599 \\
\hline França & 10 & 0,0 & 479 & 1,7 & 196 & 0,7 & 685 \\
\hline Holanda & - & - & 5 & 0,0 & 410 & 1,5 & 415 \\
\hline Japão & 256 & 0,9 & 8 & 0,0 & - & - & 264 \\
\hline Korea & 265 & 0,9 & - & - & - & - & 265 \\
\hline Argentina & 11 & 0,0 & - & - & 148 & 0,5 & 159 \\
\hline Alemanha & - & - & 75 & 0,3 & - & - & 75 \\
\hline Outros & - & - & 728 & 2,6 & 350 & 1,3 & 1.078 \\
\hline Part. estrangeira & 17.270 & 60,0 & 10.123 & 35,9 & 13,654 & 48,9 & 41.047 \\
\hline Total & 28.793 & 100 & 28.234 & 100 & 27.949 & 100 & 84.976 \\
\hline
\end{tabular}

Fonte: PND/BNDES, atualizado em 08/11/2001.

Os autores agradecem as observações e os comentários de dois pareceristas anônimos. Ressalvam que todos os erros remanescentes são de sua inteira responsabilidade.

E-mail: ricardoc@ucb.br.

E-mail:.jmn0702@unb.br.

(Recebido em julho de 2002. Aceito para publicação em agosto de 2004). 